\title{
El dilema unicameralismo-bicameralismo en la Segunda República española
}

\author{
Miguel Ángel Giménez Martínez \\ Universidad Autónoma de Madrid \\ miguelangelgimenezmartinez@gmail.com
}

RESUMEN: Una de las características esenciales del constitucionalismo español ha sido la dualidad de Asambleas, ininterrumpida desde la promulgación del Estatuto Real de 1834. La Constitución de 1931, sin embargo, vino a romper con esta tradición y se convirtió, junto con la de 1812, en la única de nuestra historia que ha creado un Parlamento unicameral. El objeto del presente trabajo es analizar las causas que llevaron a establecer una sola Cámara, lo que constituyó una de las más importantes novedades ofrecidas por la Segunda República en cuanto a la estructuración orgánica del Estado. Partimos para ello de un enfoque multidisciplinar que combina la exégesis de textos legales, el análisis de fuentes parlamentarias (los Diarios de Sesiones) y el contraste con las aportaciones doctrinales. El estudio se centra primero en el proceso de elaboración constitucional; repasa a continuación la pugna dialéctica entablada entre los partidarios del unicameralismo y los que se inclinaban por mantener la estructura bicameral de las Cortes, y concluye con una valoración final en torno a las consecuencias que el modelo elegido tuvo para la consolidación del régimen republicano y los potenciales beneficios que la conservación del Senado habría proporcionado.

\section{Palabras Clave: Segunda República española; Constitución de 1931;} Parlamento; Senado.

\section{The Dilemma Unicameralism-Bicameralism in the Spanish Second Republic}

ABSTRACT: One of the essential characteristics of the Spanish constitutionalism is the duality of Assemblies in the Cortes, uninterrupted since the promulgation of the Royal Statute in 1834. Nevertheless, the 1931 Constitution came to break this tradition and became, along with the 1812 Constitution, the 
only one in our history that has created a unicameral Parliament. The aim of this paper is to analyse the causes which led to establish a single Chamber, which was one of the main novelties the Second Republic offered regarding the State's organic structure. To do so, we start from a multidisciplinary scientific approach that combines the exegesis of legal texts, the analysis of parliamentary sources (the Journal of Debates) and the contrast with the doctrinal contributions. The study focuses first on the process of constitutional elaboration; revises next the dialectical dispute between the supporters of unicameralism and those who leaned towards maintaining the bicameral structure of the Cortes, and concludes with a final assessment about the consequences the elected model had for the consolidation of the republican regime and the potential benefits the conservation of the Senate would have provided.

KeY WORDS: Spanish Second Republic; 1931 Constitution; Parliament; Senate.

\section{INTRODUCCIÓN}

El problema de la alternativa entre unicameralismo y bicameralismo es un «tema clásico de la literatura político-constitucional» ${ }^{1}$ y plantea una de las cuestiones más importantes que definen la naturaleza de los Parlamentos. Y ello porque, generalmente, salvo alguna rara excepción ${ }^{2}$, las Asambleas representativas modernas están compuestas por una o dos Cámaras. El bicameralismo supone, en esencia, que para cambiar el statu quo es necesaria la intervención de una Cámara extra; es decir, dos Asambleas ejercen la función parlamentaria y ambas se eligen de manera diferenciada por el cuerpo electoral. En todo caso, el factor determinante del bicameralismo es que la Segunda Cámara tenga competencia legislativa general ${ }^{3}$.

Cuando fue proclamada la Segunda República, la fórmula bicameral contaba con la preferencia mostrada por todas las constituciones del Ochocientos español a partir del Estatuto Real de 18344. Así, las Constituciones de 1837, 1845, 1869 y 1876 instituyeron unas Cortes divididas en dos Cámaras, con un Congreso de los Diputados de elección popular más o menos abierta, y un

1 COTTA, 1 (Milán, 1971): 545.

2 La constitución yugoslava de 1963 estableció, por ejemplo, un sistema representativo basado en cinco Cámaras. Vid. LESAGE, 1971: 320 y ss.

3 TSEBELIS y MONEY, 1997: 43-44. Sobre los criterios de justificación del bicameralismo y los modelos clasificatorios de las Segundas Cámaras, vid. LIJPHART, 1984: 201-211, y DUVERGER, 1988: 133-137.

4 TOMÁS VILLARROYA, 1968. De hecho, el bicameralismo era uno de los aspectos básicos del «pacto liberal de orden y estabilidad» que materializaron progresistas y moderados. Vid. LARIO, 122 (Madrid, 2003): 190. 
Senado sin raíz electiva, con miembros natos, designados o cooptados dentro de ciertas corporaciones o clases ${ }^{5}$. Por el contrario, el sistema unicameral surgió con brío en la Constitución de 1812, que ponderó positivamente la radicalidad liberal de la unidad legislativa ${ }^{6}$. La polémica histórica entre unicameralismo y bicameralismo ha dejado, en fin, una larga estela de argumentaciones $\mathrm{y}$, pese a la trayectoria predominantemente bicameral del constitucionalismo español, la discusión ha reaparecido de nuevo en cada período constituyente. Por otra parte, esta ha sido siempre una cuestión inseparable de posturas políticas concretas: la mayoría de los bicameralistas fueron siempre conservadores, mientras que las posiciones unicameralistas quedaron normalmente defendidas por la izquierda ${ }^{7}$.

Coincidiendo con la crisis de la Restauración se observa un incremento de la atención sobre este punto ${ }^{8}$. Así, desde finales del siglo XIX aparecen voces entre la izquierda socialista y los sectores liberales más progresistas que abogan por la democratización del Senado, y en los primeros decenios del siglo XX comienza a negarse la propia existencia de una segunda cámara. Por un lado, algunos liberales defensores del mantenimiento de la Constitución de 1876 apuntan la necesidad de reformar la composición del Senado dotándolo de un perfil organicista ${ }^{9}$. Otras figuras progresistas, sin embargo, creerán que un simple cambio en el método de reclutamiento de los senadores no es suficiente para solventar los daños estructurales del sistema y piden reformas más profundas en el edificio constitucional ${ }^{10}$.

Los partidarios de suprimir la segunda cámara engrosan considerablemente sus filas a finales de los años veinte, con motivo de la discusión de los pro-

5 La frustración del proyecto de Constitución de la Primera República de 1873, que hacía del Senado una Cámara federal, impide saber en la práctica lo que habría supuesto un Senado no conservador. Vid. sobre ello, y en general sobre el bicameralismo en la historia constitucional española, los trabajos de BERTELSEN REPETTO, 1974; PÉREZ LEDESMA, 1995, y FERNÁNDEZ SARASOLA, 2005: 931-958.

6 SIERRA, PEÑA GUERRERO y ZURITA, 2010: 144.

7 Así lo cree también LUCAS VERDÚ, 1976, vol. 3: 320. Aunque no solo los conservadores defendieron el modelo bicameral. También los «nuevos liberales» o «liberales sociales» propugnaron la creación de un Senado en el que tuviera su asiento la «representación orgánica», que habría de ofrecer a los obreros un lugar donde discutir su problemática con los empresarios. Este modelo, introducido en España por los krausistas a mediados del siglo XIX, gozaría de un notable predicamento. Vid. al respecto LARIO, 2008: 434-443.

8 El debate ideológico surgido en torno a este tema antes del advenimiento de la Segunda República ha sido tratado por GARCÍA CANALES, 1977: 233-235.

9 Vid. SARACÍBAR, 1921; MASSANET Y BELTRÁN, 1929: 48; OSSORIO Y GALLARDO, 1930: 91; EZA, 1928: 104 y ss., o GASCÓN y MARÍN, 1928.

${ }^{10}$ Es el caso de GARCÍA GALLEGO, 1930; ROYO-VILLANOVA, 1928; ALCALÁZAMORA, 1928; GÓMEZ DE BAQUERO, 1922; TOMÁS ELORRIETA, 1929, y ZANCADA, 1930: 190-191. 
yectos constitucionales de la dictadura de Miguel Primo de Rivera, pero ya en 1907 Eugenio Cemboraín advertía de lo absurdo que resultaba una organización de la representación que «da a los senadores la misma representación que a los diputados a Cortes, lográndose únicamente con esta dualidad de Cámaras hacer la elaboración de las leyes más larga, sin obtener, en cambio, ningún resultado práctico, positivo, como no sea poner en contraposición a ambas Cámaras y, como consecuencia, a las clases cuya representación se atribuyen» ${ }^{11}$. En el mismo sentido se expresarían años después Vicente Roig Ibáñez ${ }^{12}$ y Antonio Vázquez del Campo, para quien establecer «dos Cámaras a base de sufragio universal tanto daría como buscar una repetición inútil» ${ }^{13}$.

El tema no deja de ser polémico en ningún momento y aunque a la altura de 1931 la postura predominante entre la doctrina parece seguir siendo la bicameralista, el Senado que se baraja de cara al futuro tiene un carácter muy distinto al de las Cámaras Altas del constitucionalismo decimonónico. Muy pocos son los defensores de un Senado en línea con lo establecido por la Constitución de 1876. Solo algunos políticos restauracionistas como Gabino Bugallal ${ }^{14}$, Antonio García Alix ${ }^{15}$ o Juan Muñoz Casillas ${ }^{16}$ se mostrarían partidarios de una segunda cámara elitista. Sin embargo, un Senado de estas características se encontraba ya muy desprestigiado debido a la preponderancia de la componente aristocrática en el sistema de reclutamiento de los senadores, en constante crecimiento en los últimos años de la Monarquía alfonsina por el incremento de los títulos concedidos por la Corona, irregular forma de pagar servicios y granjearse apoyos ${ }^{17}$.

Por el contrario, las fuerzas que dominan el panorama político de los años veinte y treinta no se moverán en la línea de la corriente doctrinal y de acuerdo con las inquietudes de los publicistas, sino a impulsos de motivaciones políticas, de manera que tanto los «constituyentes frustrados» de la Asamblea Nacional primorriverista como los próceres que elaboraron la Constitución republicana terminarán inclinándose en la misma dirección unicameralista. No obstante, dichas motivaciones políticas eran bien diferentes en unos y en otros. Así, los constituyentes de 1931 delinearán una Cámara hegemónica entre los poderes del Estado, capaz de sobreponerse a cualquier otra institución que se interpusiera en su objetivo de impulsar la profunda y radical transformación

11 CEMBORAÍN, 1907: 13.

12 ROIG IBÁÑEZ, 1930: 125.

13 VÁZQUEZ DEL CAMPO, 1929: 110.

14 BUGALLAL, 1929.

15 GARCÍA ALIX, 1910: 11.

16 MUÑOZ CASILLAS, 1929: 55.

${ }_{17}$ Para ACOSTA RAMÍREZ, 1999: 306, «no hay temor en afirmar que el Senado canovista desarrolla una fuerte tendencia aristocratizante en su parte permanente». 
que precisaba España. Muy al contrario, lo que los hombres de la dictadura pretendían, con la anuencia reticente de los vocales de la Sección Primera de la Asamblea, era el predominio del Ejecutivo y la formación de una cámara dócil.

La fobia del general Primo de Rivera hacia la aristocracia y el Senado - hecho curioso, dado que él mismo era Grande de España y ex senador-, era de sobra conocida. Pero cuando el dictador manifestó a los asambleístas de la Sección Primera «De Leyes Constituyentes» su apuesta por la opción unicameral no solo estaba manifestando una postura personal, sino una jugada política de largo alcance: eliminar el Senado «suspendido» en 1923 era acabar con el mayor reducto de la clase política de la Restauración, puesto que en la Cámara Alta se refugiaban buena parte de los políticos más sobresalientes del sistema que se trataba entonces de cambiar. Por lo demás, una única cámara sin miembros vitalicios era más fácilmente controlable, sobre todo si las restantes previsiones de la Constitución otorgan una gran capacidad de iniciativa y maniobra al Gobierno. El modelo unicameral de la propia Asamblea Nacional Consultiva fue un dato que condicionó a los vocales de la Sección Primera, a pesar de ser todos ellos hombres formados políticamente en los usos de la Restauración. Sin embargo, estas pretensiones fueron pobremente teorizadas ${ }^{18}$. Los argumentos doctrinales de la época no habían abandonado la preferencia por el bicameralismo y las tesis de los vocales de la Sección Primera siguieron esa línea. Éstos dejaron todo dispuesto para «desdoblar» la cámara única finalmente aprobada en el anteproyecto constitucional a través del Consejo del Reino, que en un futuro habría de tomar para sí, junto a las atribuciones de alto órgano asesor, las de Cámara Alta ${ }^{19}$.

\section{LA ESTRUCTURA DEL PARLAMENTO EN EL ITER CONSTITUYENTE}

La conveniencia de que el sistema parlamentario se desarrollara en el marco de una o dos cámaras daría lugar a intensas polémicas durante el período

${ }^{18}$ Con algunas excepciones. Así, un voluntarioso PEMÁN, 1929: 383-384, hombre próximo al dictador y teorizador de la Unión Patriótica, apoyaba su opción decididamente unicameral en que «si las instituciones son algo más que sus formas externas, el bicameralismo no existe ya en Inglaterra, porque la esencia del sistema, que no puede ser la dualidad accidental y material de Cámaras, sino la dualidad de potestades, ha desaparecido allí». Por otro lado, desde las páginas del diario católico El Debate, MINGUIJÓN, 1928 no albergará temor a que una Cámara única degenerara en Convención revolucionaria, ya que el conjunto del sistema político que la había de acompañar impediría este deslizamiento, porque se habrá «desplazado el eje político que antes se situaba en el Parlamento» y porque «suprimida una Cámara, queda hueco [...] para la creación de un alto Tribunal político o Consejo de Ciento que asesore al Monarca caso de discrepancia entre el Parlamento y el Poder ejecutivo».

${ }^{19}$ GARCÍA CANALES, 1980: 440. 
de elaboración de la Constitución de 1931, las cuales se prolongarían a lo largo de todo el período republicano. Ya desde el primer momento el problema se planteó como una decisión que traería serias consecuencias para el funcionamiento del régimen. La primera huella del conflicto se encuentra en el Anteproyecto de Constitución de la República Española (ACRE) elaborado por una Comisión Jurídica Asesora nombrada a instancias del Gobierno provisional ${ }^{20}$. En dicho anteproyecto se optó, mediante una débil mayoría en su seno $^{21}$, por una solución bicameral, con un Senado de base corporativasindical que completara la representación política del Congreso de los Diputados con una cierta representación de intereses. La segunda cámara tendría 250 miembros: 50 elegidos por las provincias o por las regiones; 50 por las representaciones obreras de la agricultura, la industria y el comercio; 50 por las representaciones patronales; 50 por las asociaciones de las profesiones liberales; y 50 por las Universidades, centros de enseñanza y confesiones religiosas 22 .

El Senado del ACRE tenía carácter indisoluble y cada uno de sus grupos se renovaba por mitades cada cuatro años ${ }^{23}$. Además, se le reconocía la iniciativa legislativa, junto al Gobierno y el Congreso, si bien no poseía capacidad de veto sobre los proyectos aprobados por la Cámara Baja: cualquier texto iniciado o devuelto por el Senado podía ser definitivamente aprobado en el Congreso con el voto de la mayoría absoluta de los diputados ${ }^{24}$. Así pues, como apuntaba el presidente de la Comisión Jurídica Asesora, Ángel Ossorio, en la exposición previa al ACRE, el Senado del anteproyecto era «muy distinto del que conocemos. Tiene un carácter corporativo, $[. .$.$] no tiene verdadera$ función política; interviene en la confección de las leyes como elemento reflexivo y moderador, pero las deja a la votación decisiva del Congreso; en fin, no da ni niega confianza a los Gobiernos ${ }^{25}$.

${ }^{20}$ Los miembros de la Subcomisión encargada de redactar el anteproyecto de Constitución, integrada en la Comisión Jurídica Asesora, nombrados por Decreto de 9 de mayo de 1931 (Gaceta de Madrid, no 135, de 15 de mayo de 1931, p. 743) fueron: Ángel Ossorio y Gallardo (presidente), Valeriano Casanueva, Nicolás Alcalá Espinosa, Javier Elola, Alfonso García-Valdecasas, Manuel Pedroso, Adolfo Posada, Antonio Rodríguez Pérez, Francisco Romero Otazo, Agustín Viñuales (vocales), Luis Lamana, Antonio Luna y Juan Lladó (secretarios técnicos). A finales del mes de junio esta Subcomisión presentó su dictamen al Pleno de la Comisión Jurídica que, tras dos sesiones, lo aprobó con escasas enmiendas y lo elevó al Gobierno. Vid. GARCIAA-VALDECASAS, 31-32 (Madrid, 1983): 59.

${ }^{21}$ El voto particular encabezado por Matilde Huici a todo el Título IV del anteproyecto postulando la supresión del Senado obtuvo en la Comisión Jurídica Asesora dos votos menos que el dictamen definitivo. Vid. VARELA DÍAZ, 1978: 114.

22 ACRE, art. 37.

${ }^{23} A C R E$, art. 38.

${ }^{24} A C R E$, art. 43.

${ }^{25}$ Cit. en JULIÁ, 2009: 168. 
Se impuso, de esta forma, el parecer del que era portador cualificado Adolfo Posada. Para el krausista asturiano, las Cortes debían contener un doble tipo de representatividad: la política, o abstracta, que era el resultado de una concepción democrático-liberal individualista, y en la que la opinión pública general debía estar representada de forma indiferenciada, y, por otra parte, una representatividad corporativa, en la que hallasen acomodo los distintos grupos profesionales, o lo que Posada llamaba la «constitucionalización de la representación política de intereses sociales» ${ }^{26}$. La base de esta idea corporativa se hallaba en el organicismo krausista, del que Posada era un sobresaliente defensor. Para el krausismo la idea individualista típicamente liberal debía completarse con una visión organicista de la sociedad, en la que habían de tenerse en cuenta los distintos grupos en los que los sujetos se organizaban, ya de forma natural (municipios y familias), ya artificial (asociaciones y sindicatos), como había sostenido Francisco Giner de los Ríos ${ }^{27}$. Pues bien, tanto el individuo así considerado, como los grupos en los que se integraba eran igualmente merecedores de su propia representatividad, lo que obligaba a duplicar las cámaras.

Esta solución no llegaría, sin embargo, muy lejos, pues la Comisión de las Cortes encargada de elaborar el Proyecto de Constitución de la República Española (PCRE) se inclinaría, aunque también por muy escasa mayoría, por la Cámara única ${ }^{28}$. La Comisión constitucional desechó, en este punto, el ACRE y trabajó, por el contrario, sobre la base del voto particular encabezado por Matilde Huici. Así, el PCRE estableció el unicameralismo con los votos particulares y enmiendas favorables al Senado $^{29}$ de José María Gil-Robles (agrario) y Jesús María de Leizaola (nacionalista vasco) ${ }^{30}$, Ricardo Samper y Justo Villanueva (ambos radicales) ${ }^{31}$, Juan Castrillo (progresista) ${ }^{32}$, Manuel

${ }^{26}$ POSADA, 1931: 129.

27 «No hay sociedad, pues, ni organicismo, en una serie indefinida de individuos con una o varias notas comunes, como no lo hay siquiera en una muchedumbre accidentadamente reunida en un determinado lugar y para un determinado fin; sino una mera colectividad, que no forma cuerpo». GINER DE LOS RÍOS, 1899: 195.

${ }^{28}$ La Comisión parlamentaria estaba formada por cinco miembros de la minoría socialista, entre ellos el presidente, Luis Jiménez de Asúa; cuatro del grupo radical; tres por los radical-socialistas; dos por Esquerra Republicana de Catalunya; y uno por cada una de las minorías agraria, federal y vasco-navarra, Agrupación al Servicio de la República, progresista, Federación Republicana Gallega y Acción Republicana. La lista completa la refiere JIMÉNEZ DE ASÚA, 1932: 34-35.

${ }^{29}$ Un análisis del contenido de estas enmiendas y votos particulares en RUIZ LAPEÑA, 7 (Zaragoza, 1998): 344-346.

30 Diario de Sesiones de las Cortes Constituyentes (DSCC), ap. $5^{\circ}$ al $\mathrm{n}^{\mathrm{o}} 24$, de 20 de agosto de 1931.

${ }^{31}$ DSCC, ap. $12^{\circ}$ al n 24 , de 20 de agosto de 1931.

32 DSCC, ap. $10^{\circ}$ al n 26 , de 25 de agosto de 1931. 
Ayuso (federal) ${ }^{33}$, Antonio Royo-Villanova (agrario) ${ }^{34}$, José Terrero (radi(al) $)^{35}$ y Bernardino Valle (federal) ${ }^{36}$.

El 27 de octubre de 1931, al discutirse el artículo 49 del PCRE, se acordó la supresión del Senado por 150 votos contra $100^{37}$. El carácter monopolista y exclusivo del Congreso de los Diputados quedó así reforzado por completo. Y ello se debió, sobre todo, a las preocupaciones por fortalecer y democratizar las instituciones parlamentarias. Mientras que los defensores del Senado utilizaron argumentos de índole técnica y funcional, los partidarios de la cámara única se apoyaron fundamentalmente en el radicalismo democrático que impregnaba buena parte de la ideología republicana. El artículo 51 de la Constitución de 1931, siguiendo el modelo de la Constitución de Cádiz, afirmaba de forma taxativa que «la potestad legislativa reside en el pueblo, que la ejerce por medio de las Cortes o Congreso de los Diputados».

\section{LA APUESTA POR EL UNICAMERALISMO: POSTURAS A FAVOR Y EN CONTRA}

El criterio adoptado por los constituyentes de 1931 era idéntico al que impulsó la generalización del unicameralismo en el nuevo constitucionalismo europeo posterior a la Gran Guerra ${ }^{38}$. Por entonces ya era indudable la decadencia de los Senados, que habían pasado de ser segundas cámaras a «Cámaras secundarias ${ }^{39}$, y predominaban las modernas tesis de Carl Schmitt, para quien la democracia era incompatible con la dualidad de cámaras: «Para la Constitución democrática la cuestión del sistema bicameral se reduce a una clara alternativa: o bien han de encontrar su expresión en la segunda Cámara singularidades substanciales, dignas de aprecio, dentro del pueblo - especial formación, especial experiencia, edad, riqueza, propiedad inmueble-, y entonces significa ese sistema una vulneración de la igualdad y homogeneidad democrática de todos los ciudadanos, o bien no se trata de diferencias y singularidades esenciales, y entonces no se ve por qué ha de irse a la formación de una Cámara especial» ${ }^{40}$.

${ }^{33}$ DSCC, ap. $4^{\text {o }}$ al no 39 , de 16 de septiembre de 1931.

${ }^{34}$ DSCC, ap. $8^{\circ}$ al n ${ }^{\circ} 60$, de 21 de octubre de 1931.

${ }^{35}$ DSCC, ap. $8^{\circ}$ al n ${ }^{\circ} 62$, de 23 de octubre de 1931.

${ }^{36}$ DSCC, n $^{\circ}$ 63, de 27 de octubre de 1931, p. 1.942.

37 El nivel de abstenciones fue muy alto, y alcanzó a más del $40 \%$ de la Cámara. En torno a esta cuestión, CASTILLO ALONSO, 1932: 375, hizo notar que «una minoría de la Asamblea decidió tan trascendental problema en el que, al decir del señor Alcalá-Zamora en la Cámara, "está la vida de la República"».

38 Sobre el declive del bicameralismo en la Europa de entreguerras y su influencia en la Constitución de 1931, vid. JIMÉNEZ DE ASÚA, 1932: 66-67.

${ }^{39}$ MCBAIN y ROGERS, 1922: 38.

${ }^{40}$ SCHMITT, 1934: 342. 
Sin embargo, lo particular del caso español es que un simple recuento de las opiniones manifestadas por los diputados en las Cortes Constituyentes indica que los partidarios del Senado no estaban en minoría y que, de ninguna manera, es cierta la impresión de una línea definida que separara a defensores y enemigos de una segunda cámara. El ambiente, en un principio, parecía favorable a las dos Cámaras, pero, como apreciaba el cronista parlamentario Arturo Mori, «ya se ha visto otras tardes que, en un momento dado, cuando menos se espera, surge el incentivo izquierdista y ocurren las cosas de modo muy distinto a como se iniciaran» ${ }^{41}$.

Pueden identificarse tres circunstancias que impidieron el éxito final de esas opiniones favorables. En primer lugar, la inhibición de algunos grupos de derecha que, tras la aprobación del polémico artículo 26 de la Constitución, sobre la cuestión religiosa, decidieron abandonar las sesiones. Con esa actitud, al llegar los debates sobre la organización del Estado, las propuestas para el establecimiento del Senado se vieron privadas de unos votos que hubieran podido ser decisivos. Gil-Robles, intentando justificar el retraimiento de los agrarios en el Pleno que rechazó el Senado, afirmó muchos años después que «aprobados los artículos referentes a la religión, familia, enseñanza, etc., la Constitución quedaba tan radicalmente inadmisible que cualquier mejora en la parte orgánica no podía mejorar nuestra actitud. Para nosotros era incluso deseable que al sectarismo dogmático se añadiese el absurdo orgánico, que hiciera más patente la necesidad de la reforma. Por otra parte, ¿quién se atreverá a decir que el sistema bicameral es preferible - máximo en los tiempos modernos- a la Cámara única? $\rangle^{42}$. Un alegato, en realidad, absurdo, pues, como se dijo antes, el autor fue signatario de un voto particular al proyecto de Constitución en el que proponía, precisamente, el establecimiento del Senado.

En segundo término, las diferencias surgidas en torno a la configuración de la segunda cámara entre sus partidarios debilitaron considerablemente sus energías. Así, mientras una mayoría de Grupos Parlamentarios estaba decidida a introducir alguna forma de bicameralismo, no fueron, sin embargo, capaces de llegar a coincidir sobre la composición y facultades del Senado. Al iniciarse los debates sobre la totalidad del dictamen constitucional, se mostraron partidarios de introducir dos Cámaras las siguientes fuerzas políticas: Federación Republicana Gallega (FRG), Partido Republicano Progresista (PRP), Partido Republicano Democrático Federal (PRDF), Esquerra Republicana de Catalunya, Partido Republicano Radical (PRR), Partido Republicano Liberal Demócrata (PRLD), Partido Republicano Radical Socialista (PRRS), los agrarios y la minoría vasco-navarra. En contra se mostraron desde el principio

\footnotetext{
${ }^{41}$ MORI, 1932, vol. 4: 9.

${ }^{42}$ GIL-ROBLES, 1968: 55.
} 
el Partido Socialista Obrero Español (PSOE) ${ }^{43}$, Acción Republicana (AR) y la Agrupación al Servicio de la República (ASR). Estas posiciones se mantendrían prácticamente inalterables en todo momento a excepción de la manifestada por los radical-socialistas, que, por boca de Félix Gordón Ordás, comenzaron proponiendo un «Consejo Económico Federal» y acabaron engrosando, en los momentos decisivos, la lista de votantes favorables al unicameralismo ${ }^{44}$.

En tercer y último lugar, la rígida disciplina interna del Grupo Parlamentario Socialista impediría a un sector importante de éste engrosar las filas de los bicameralistas. En efecto, la opinión del PSOE sobre el tema no era, ni mucho menos, unánime, pues destacadas figuras del partido abrigaban el deseo de completar la representación política e ideológica con la de los intereses económicos y sociales. Son los casos de Julián Besteiro y Fernando de los Ríos, «discípulos de Giner de los Ríos que sirven de puente, más o menos coherente, entre krausismo y socialismo ${ }^{45}$.

En los años veinte, Besteiro pedía la «supresión del Senado tal y como actualmente está constituido, y su substitución por una Cámara corporativa en la que no tengan participación alguna las categorías sociales que carecen de significación en la vida actual. Las Corporaciones que únicamente deben tener acceso a esta Cámara son las que reflejan la organización del trabajo nacional, sin distinción, naturalmente, entre el trabajo manual y el de la inteligencia» ${ }^{4}$. La representación por profesiones u oficios, ese «Parlamento industrial» que equilibrara el «individualismo infecundo» de las cámaras inorgánicas hasta entonces usuales está también en Fernando de los Ríos, para quien las Cortes debían constar de dos cámaras, una en representación de los partidos políticos y otra en representación de los intereses de clase. Ambas harían explícita la doble dimensión del hombre en sociedad: la existencia de unos intereses generales y, junto a ellos, la presencia de unos intereses de clase no abstractos. La Cámara Baja, en cuanto representación general, debía ser la cámara propiamente política, en tanto que la Alta, por su particularismo, debía ser una cámara ante todo administrativa ${ }^{47}$.

Ahora bien, ni Julián Besteiro ni Fernando de los Ríos respondían en este punto al común sentir del socialismo español, y sus planteamientos, sobre todo los del primero, fueron ampliamente derrotados en el seno de la minoría socialista frente a los de Indalecio Prieto. Y es lógico que así ocurriera, pues para la mayoría de los socialistas «todo cuanto se asemejara al corporativismo

${ }^{43}$ Hay que tener en cuenta que el unicameralismo era un punto que figuraba específicamente en el programa electoral socialista de 1931. Vid. CONTRERAS, 1981: 287.

${ }^{44}$ DSCC, $\mathrm{n}^{\mathrm{o}} 30$, de 1 de septiembre de 1931, p. 709.

45 GARCÍA CANALES, 1977: 69.

46 BESTEIRO, 1928: 19.

47 ZAPATERO, 1974: 249-297. 
estaba condenado de antemano por sus profundas implicaciones políticas con la ideología de los conservadores, incluso por contrarrevolucionaria ${ }^{48}$. Los consejos técnicos del PCRE no fueron sino una tímida concesión inicial, muy criticada después, a este sector. Por ejemplo, Adolfo Posada recordaba que no había «nada más perturbador que una política de técnicos» y que, en todo caso, «la técnica y los técnicos deben estar prudentemente al servicio de la política de los políticos, teniendo sin duda una influencia sobre la política, pero sin la posibilidad de servir de freno o de condición indispensable, para que funcione el órgano que se cree - lo sea o no- representativo de la soberanía $\iota^{49}$. No obstante, cara al exterior, la unidad del socialismo se mantuvo sin fisuras a lo largo de todo el proceso constituyente, lo cual favoreció que la influencia del PSOE sobre la Constitución de 1931 fuera mucho mayor de la que le hubiera correspondido según su estricta fuerza numérica en las Cortes ${ }^{50}$.

La aprobación final de la fórmula unicameral no supondría, sin embargo, que cesaran los esfuerzos por introducir el Senado en el sistema parlamentario. Una de las banderas políticas más utilizadas durante los años posteriores fue la de la revisión constitucional y, dentro de ella, el bicameralismo era uno de los puntos a que se aludió con mayor insistencia. El principal propulsor de esos esfuerzos revisionistas sería el propio presidente de la República, Niceto Alcalá-Zamora, para quien, si la reforma de la Constitución fue una obsesión desde el momento en que tomó posesión de su cargo, la Cámara única era «el defecto más grave entre todos los que contiene la ley fundamental» ${ }^{51}$.

Los defensores de la segunda cámara, especialmente los conservadores, como Alcalá-Zamora, atendieron preferentemente a razones de orden técnico, sobrevalorando su carácter de contrapeso en las relaciones de poder. Y, al mismo tiempo, quienes deseaban imprimir mayores dosis de pragmatismo a la política republicana no siempre pensaron en el Senado como un instrumento eficaz para sus propósitos. A este respecto, sirvan de ejemplo las distintas actitudes de dos figuras del nuevo régimen, Julián Besteiro y José Ortega y Gasset. Ambos, desde los primeros momentos, vislumbraron claramente la necesidad de compensar la exaltación de los principios ideológicos y morales mediante fórmulas más utilitarias de compromiso.

Nada más ser elegido presidente de las Cortes, Besteiro exhortaba a los diputados «a considerar la conveniencia de tratar todos los más graves problemas que puedan presentársenos desde un punto de vista económico». Y así,

${ }^{48}$ LAMO DE ESPINOSA y CONTRERAS, 1990: 310.

49 POSADA, 1932: 179-180.

${ }^{50}$ Años después, en el exilio, VIDARTE, 1976: 183, recordaba cómo, en una reunión de la comisión ejecutiva del PSOE, oyó decir a Prieto «que él estuvo en aquella ocasión obcecado, ya que era Besteiro quien tenía razón. Igual hemos pensado, después, yo y otros muchos diputados que votamos entonces en contra».

${ }^{51}$ ALCALÁ-ZAMORA, 1936: 108. 
por ejemplo, refiriéndose más tarde a la reforma agraria, afirmaba: «si buscamos la fórmula jurídica como un resultado del tratamiento económico de ésta y otras cuestiones semejantes, ¡ah!, entonces es posible que nuestras discusiones sean mucho más serenas, y sean, también, mucho más fecundas en resultados $\rangle^{52}$.

Por su parte, Ortega, tres días más tarde, se refería en su primera intervención parlamentaria a las anteriores palabras de Besteiro para suscribirlas plenamente, y añadía: «Tenemos que hacer la democracia que hoy es posible y solo eso. Pues bien: mientras la antigua era linfática, barroca y lentísima, la actual tiene que ser magra, acerada, urgentísima. Por eso es preciso evitar toda pérdida de tiempo y de esfuerzo [...]. Nada de divagaciones ni de tratar frívolamente problemas, que solo una labor de técnica difícil puede aclarar; sobre todo, nada de estultos e inútiles vocingleros, violencias en el lenguaje o en el ademán. Porque es de plena evidencia que hay, sobre todo, tres cosas que no podemos venir a hacer aquí: ni el payaso, ni el tenor, ni el jabalí» ${ }^{53}$. La lucidez y coherencia del socialista fueron mayores, en este caso, en cuanto sus exhortaciones al pragmatismo político iban acompañadas de una defensa ferviente del bicameralismo. Contrariamente, Ortega demostraría, en este problema concreto, cierta cortedad de miras políticas al confesar en las Cortes su incomprensión de «cómo hay alguien que todavía defiende la necesidad de una segunda cámara» ${ }^{54}$.

\section{LOS BICAMERALISTAS}

La estructura del Parlamento fue objeto de importantes debates en las Cortes Constituyentes ${ }^{55}$, como correspondía, en palabras de Luis Jiménez de Asúa, a «un asunto de gran densidad y volumen ${ }^{56}$. En este sentido, las críticas lanzadas contra el unicameralismo pueden diferenciarse en dos grandes grupos. De un lado estaban quienes, frente a los argumentos de los que querían preservar la integridad de la representación democrática mediante una cámara única, oponían que «la parte orgánica de la nueva Constitución no revela en el sistema de las instituciones toda la influencia del sentido social contenida en la dogmática ${ }^{57}$. Eran los mismos que se extrañaban de que «las Constituyen-

${ }^{52}$ DSCC, $\mathrm{n}^{\circ} 9$, de 27 de julio de 1931, p. 158.

${ }^{53}$ DSCC, $\mathrm{n}^{\circ} 12$, de 30 de julio de 1931, p. 244.

${ }^{54}$ DSCC, $\mathrm{n}^{\mathrm{o}} 33$, de 4 de septiembre de 1931, p. 778.

55 Vid. FERNÁNDEZ SEGADO, 1981: 526-527; TORRES DEL MORAL, 1988: 188189, y FRAILE CLIVILLÉS, 1975: 354-365.

${ }^{56}$ DSCC, $\mathrm{n}^{\mathrm{o}} 28$, de 27 de agosto de 1931, p. 646.

${ }^{57}$ POSADA, 1932: 234. 
tes, de un carácter socialista tan acentuado, no hayan querido incorporar las fuerzas sindicales a la Constitución ${ }^{58}$. Eran, en definitiva, quienes pensaban que el Senado no solo no disminuiría, sino que completaría el carácter representativo del Parlamento: para unos, dando entrada a los intereses económicos y sociales; para otros, siendo el corolario de la estructura regional o federal del Estado que propugnaban.

De otra parte, alcanzaron mucha mayor audiencia los argumentos funcionales, es decir, aquellos que consideraban la segunda cámara como un elemento compensador o atenuante de los eventuales excesos de la primera, evitando al jefe del Estado los roces constantes con el Parlamento; eran las conocidas disquisiciones sobre las ventajas moderadoras que proporciona un doble tratamiento de las leyes y sobre la estabilidad política que dimana de una «aristocracia» senatorial frente a los posibles vaivenes que se experimentan en una Cámara Baja: «Un jurista que hubiese vivido fuera de España durante el primer cuatrienio de la República habría podido, para los más de los casos, prescindir de los anuarios legislativos, porque el balance final de éstos era derogación, cero, y las más de las instituciones seguían teniendo por norma, excluida la ley fundamental, los preceptos de la monarquía parlamentaria, cuando no los de la absoluta dictatorial. Con un Senado, la obra legislativa de las Constituyentes no habría ido tan a la izquierda, pero entonces ni la reacción de 1933 habría sido tan intensa, ni la Cámara senatorial le abría permitido inclinarse, decididamente, hacia la derecha. España, la República y su legislación, dando menos pasos, $\mathrm{y}$, desde luego, menos violentos, habrían adelantado incomparablemente más $\rangle^{59}$.

Discutido el proyecto constitucional en el pleno de la Cámara, las opciones por el bicameralismo y el unicameralismo entraron abiertamente en liza. Los grupos conservadores acudieron al argumento tradicional: la experiencia histórica demostraba el valor de un Senado para templar las acometidas democráticas de una Cámara Baja que, en ausencia de contrapeso, podía convertirse en una Asamblea tiránica, siendo la dictadura parlamentaria la peor de las posibles. Así, las derechas se aferraron a las teorías procedentes de la balanced constitution británica (difundidas desde el siglo XVIII por autores como De Lolme, Montesquieu, Blackstone o Bolingbroke, entre otros) que entendía el Senado como Cámara de equilibrio constitucional ${ }^{60}$. A la hora de configurar este Senado, sin embargo, no se podía seguir manteniendo la composición en la que se había basado la idea clásica de armonía constitucional (la aristocracia como freno de la democracia). En pleno siglo XX, postular una

58 POSADA, 1932: 245.

59 ALCALÁ-ZAMORA, 1936: 110.

${ }^{60}$ Sobre la recepción de este concepto en España, vid. VARELA SUANZESCARPEGNA, 1997: 97-124; y FERNÁNDEZ SARASOLA, 1996: 248-249; 2009, 181-182. 
representación aristocrática —y más aún en el seno de una revolución política como la de 1931 - resultaba una propuesta anticuada condenada al fracaso ${ }^{61}$.

Los conservadores defendieron el parecer del anteproyecto, a saber, una Cámara Alta de carácter corporativo, aunque lo cierto es que resultaba muy difícil de justificar por qué una composición de esta índole sería idónea para templar los supuestos excesos de la Cámara Baja. Entre los defensores del Senado corporativo, uno de los más brillantes sería Niceto Alcalá-Zamora (PRP), a la sazón presidente del Gobierno provisional. Sus argumentos para defender el bicameralismo se abrían en diversos frentes: la forma de Estado, la forma de Gobierno y la organización territorial proclamados en la Constitución. Todo ello conducía necesariamente al establecimiento de una Segunda Cámara, aunque, en realidad, el punto de partida de Alcalá-Zamora era, ante todo, la idea de crear una Cámara conservadora y de equilibrio.

En efecto, en primer lugar, para Alcalá-Zamora, habiéndose establecido una República, el bicameralismo se convertía en un imperativo. En un Estado monárquico, la propia Corona aseguraba la continuidad necesaria en la vida política. Sin embargo, al establecerse una República democrática, se estaba introduciendo un factor de constante cambio - derivado de las elecciones-, que debía contar con un contrapeso de estabilidad. Éste no podía ser otro más que el Senado ${ }^{62}$. En segundo lugar, la forma parlamentaria de Gobierno exigía, para mantenerse como tal, de la presencia del Senado. Puesto que había que buscar un contrapeso al Parlamento, si no existía una segunda cámara el equilibrio tendría que procurarlo el presidente de la República, para lo cual era preciso dotarlo de grandes competencias que mutarían el parlamentarismo en presidencialismo. Para evitarlo, la única salida se hallaba en formar un Senado al que se dotara de veto $\mathrm{y}$, por tanto, se le permitirse frenar a la Cámara Baja, en lugar de hacerlo el presidente ${ }^{63}$.

Finalmente, Alcalá-Zamora justificaba su defensa del Senado en dos características del proyecto constitucional: su carácter social y la organización territorial descentralizada. Por lo que se refiere al primer aspecto, siendo el texto claramente avanzado desde el punto de vista económico y social, resultaba lógico dar representación a los grupos de interés - asociaciones profesionales, sindicatos, empresarios, etcétera - ${ }^{64}$. En cuanto a la organización territorial, bien es cierto que España no se proclamaba un Estado federal, pero sí «federalizante», al establecerse un Estado integral en el que las regiones podían tener competencias muy amplias y asimiladas a las de los Estados

\footnotetext{
${ }^{61}$ FERNÁNDEZ SARASOLA, 2008: 316.

${ }^{62} D S C C, \mathrm{n}^{\circ} 63$, de 27 de octubre de 1931, p. 1.949.

${ }^{63} D S C C, \mathrm{n}^{\mathrm{o}}$ 63, de 27 de octubre de 1931, p. 1.954.

${ }^{64}$ DSCC, $\mathrm{n}^{\mathrm{o}}$ 63, de 27 de octubre de 1931, p. 1.951.
} 
miembros de una Federación. En consecuencia, también a las regiones debía dárseles representación en el Senado, que, de esta forma, se convertía en una Cámara mixta, en la que se agrupaban una representación profesional y otra territorial ${ }^{65}$.

Varios diputados defendieron el bicameralismo a partir de posturas bastante parecidas a las de Alcalá-Zamora. Así, Antonio Royo-Villanova acudió de nuevo al argumento de la forma de Estado (República) y la forma de gobierno (parlamentarismo) para defender el Senado ${ }^{66}$. Al parecer del diputado agrario por Valladolid, el jefe del Estado había de ser elegido por el Parlamento, pero la Asamblea debía entonces ser bicameral, ya que, de lo contrario, el presidente de la República acabaría por convertirse en un mero mandatario de las Cortes, transformándose el sistema parlamentario en asambleario.

Otro eje argumental de los diputados partidarios de la introducción de una segunda cámara se apoyaba en la necesidad de arbitrar una representación de intereses, orgánica, aún imprecisamente corporativa, que viniera a completar la representación individual, ideológica y partidista. Dentro de esta línea de razonamiento, que aspiraba a superar la concepción individualista de la representación, se alegaban las ventajas de una mayor capacidad técnica, y una mayor autenticidad en la opinión de los representantes venidos a la Cámara por su condición de profesionales, de miembros de asociaciones o corporaciones, de vecinos de una determinada circunscripción territorial más o menos natural o histórica, etcétera ${ }^{67}$.

Pero es en Melquíades Álvarez (PRLD) donde se hallan los argumentos de mayor peso y más en consonancia con las preocupaciones doctrinales de la época: «Sabe mejor que yo mi ilustre compañero el señor ministro de Justicia [Fernando de los Ríos] que hoy se habla [...] de la existencia del grupo social como nuevo método en política y base del futuro sistema industrial y económico de los países. Y hasta se llega a decir que en esta sociedad total que se llama la Nación va surgiendo, cada día con mayor vigor, ese tejido complejo de gremios, de sindicatos, de asociaciones, de comunidades locales que encarnan y representan intereses, nada más que intereses, y que, de prevalecer, algún día podrían poner en peligro la voluntad general de la Nación». Álvarez avisaba del peligro que, en su opinión, ya prevenía Rousseau en su Discours sur l'économie politique: que los «intereses particulares no modificaran o engañaran la voluntad colectiva del país». De aquí que debiera evitarse que

${ }^{65}$ DSCC, $\mathrm{n}^{\circ} 63$, de 27 de octubre de 1931, p. 1.948.

${ }^{66}$ DSCC, $\mathrm{n}^{\mathrm{o}} 62$, de 23 de octubre de 1931, pp. 1.911-1.914.

${ }^{67} \mathrm{Vid}$. como ejemplo de esto el ya mencionado voto particular de Gil-Robles y Leizaola (DSCC, ap. $5^{\circ}$ al $\mathrm{n}^{\circ} 24$, de 20 de agosto de 1931), la intervención en el Pleno del diputado de la FRG Roberto Novoa Santos (DSCC, $\mathrm{n}^{\circ} 31$, de 2 de septiembre de 1931, pp. 724-729), o la del progresista Carlos Blanco (DSCC, n 31, de 2 de septiembre de 1931, p. 731). 
los intereses económicos, que tanta pujanza habían alcanzado en las nuevas sociedades, pudieran «desarrollarse clandestinamente, conspirando en el silencio contra los intereses del Estado; estos intereses tienen necesidad de representarse, pero de representarse en el Estado, para que el Estado temple sus rigores y sus exigencias con fórmulas de justicia que los intereses no pueden dar por sí mismos». Estas eran, en fin, las razones por las que defendía «una segunda cámara que sea representativa de estos elementos corporativos ${ }^{68}{ }^{6}$.

Por otro lado, los partidarios de la doble Cámara encontraron en los federalistas y regionalistas o autonomistas aliados muy válidos. Desde los primeros momentos hubo una predisposición en éstos a ubicar la representación territorial en el Senado, y tanto en la ponencia de la comisión jurídica asesora como en las enmiendas y votos particulares de la comisión de Cortes se hizo patente esta tendencia. El diputado Manuel Ayuso, por el sector federal de la Cámara, comenzó haciendo una firme defensa de la representación política individual para venir seguidamente a la defensa de un Senado corporativo y de base territorial: «Se necesita el Senado para que vayan allí democráticamente las representaciones de las regiones. Si habéis comenzado por reconocerlo, ¡no sé si de buen grado o por la fuerza! Ahí están los Estatutos de Cataluña, de Galicia, de Vasconia, etcétera. ¿Dónde vais a llevar la voz parlamentaria de estos grupos regionales? Además, ¿dónde han de ir las representaciones de los sindicatos y sus federaciones? ${ }^{69}$.

Las razones de fondo para defender el Senado se redujeron en muchos diputados, confesadamente, al propósito de lograr un desarrollo equilibrado de la República; «aun cuando quepa sospechar que en otros había también una intención plenamente conservadora de la situación social y económica, así como el intento de preservar la influencia política de los grupos hasta el momento dominantes $\rangle^{70}$. Otro argumento se referirá al perfeccionamiento del proceso legislativo, de modo que el Senado, lejos de significar una obstrucción o inconveniente reiterativo, pudiera ser un tamiz de gran valor político, tanto para el acierto como para la estabilidad de la República. De aquí que

${ }^{68}$ DSCC, $\mathrm{n}^{\mathrm{o}} 35$, de 9 de septiembre de 1931, p. 821.

${ }^{69}$ DSCC, $\mathrm{n}^{\circ}$ 63, de 27 de octubre de 1931, p. 1.964. En el mismo sentido, un hombre de profunda raigambre federal como Joaquín Pi y Arsuaga, hijo de Francisco Pi y Margall y diputado por Barcelona (capital), publicaba por entonces en El Mercantil Valenciano la reseña de lo que fue la actuación de su grupo político, el PRDF, en las Constituyentes: «Nosotros abogamos, como no podíamos menos de hacerlo, a fuer de federales, por dos Cámaras: el Congreso, verdadero poder legislativo; el Senado, o como quiera llamarse, compuesto por las representaciones regionales y de las Artes, la Industria, la Agricultura, tamiz por donde había de pasar la labor legislativa para evitar que las leyes pudiesen menoscabar las libertades individuales, los preceptos constitucionales, las relaciones y los intereses regionales». Cit. en ROYO-VILLANOVA, 1934: 156.

${ }^{70}$ GARCÍA CANALES, 1977: 240. 
algunos diputados, como Melquíades Álvarez, pidieran «una Cámara Alta que modere el impulso reformador, extraordinariamente reformador de la Cámara popular; que establezca el equilibrio entre esos ímpetus revolucionarios y lo que pudiéramos llamar el impulso de conservación $\rangle^{71}$.

Finalmente, un último razonamiento utilizado como de peso por los bicameralistas, y bajo la amenaza de que de no ser atendido se podría llegar a una efectiva degradación de los ideales republicanos, es el de que el Senado salvaguardaría al naciente régimen de vaivenes bruscos y peligrosos tales como los intentos dictatoriales o de autoritarismo presidencial. El peligro del que se prevenía podría proceder de una cámara que se revolviera demagógicamente retadora frente a los órganos del Estado, de una presidencia de la República que, enfrentada con la cámara, optara por apelar al asentimiento popular plebiscitario, o de un golpe de fuerza exterior al sistema constitucional. En este sentido, si Melquíades Álvarez advertía contra el posible «despotismo parlamentario» ${ }^{72}$, Alcalá-Zamora afirmaba rotundamente: "Cámara única no, porque la Cámara única es la duda única de cómo se eclipsará la libertad republicana» ${ }^{73}$.

\section{LOS UNICAMERALISTAS}

El bicameralismo fue defendido con argumentos clásicos, que se habían esgrimido en todos los procesos constituyentes españoles y con argumentos nuevos que empezaban a utilizarse en ciertos ámbitos académicos y en otros países $^{74}$. Sin embargo, se impuso el criterio unicameral, apoyado en consideraciones de muy diverso signo que sintetizó Jiménez de Asúa en su discurso de presentación del proyecto de Constitución ante las Cortes. En concreto, adujo estas cinco razones: $1^{\mathrm{a}}$, consideraba a las Cámaras Altas como un «recuerdo de antaño que el tiempo barrerá», ya que "van cayendo y quedando como huellas y residuos»; $2^{\mathrm{a}}$, estimaba que el sistema bicameral es «sobremanera nocivo», porque «obstaculiza las leyes progresivas», retrasando el profundo cambio que necesitaba la sociedad española; $3^{\mathrm{a}}$, también era perjudicial porque los previsibles enfrentamientos entre ambas cámaras se convertirían en un estorbo para la buena marcha de la actividad legislativa, debilitando al Parlamento, que podía de esta manera ser «pasto de un poder ejecutivo acometedor»; $4^{\mathrm{a}}$, en otro orden de ideas, argumentaba que la dualidad de Cámaras era contraria al ideal democrático, ya que «éste descansa en el supuesto de la igualdad del pueblo como unidad y una Cámara Alta pondría

${ }^{71}$ DSCC, n $^{\circ} 35$, de 9 de septiembre de 1931, p. 821.

${ }^{72}$ DSCC, $\mathrm{n}^{\circ} 35$, de 9 de septiembre de 1931, p. 821.

${ }^{73}$ DSCC, $\mathrm{n}^{\mathrm{o}}$ 63, de 27 de octubre de 1931, p. 1.955.

74 TOMÁS VILLARROYA, 1981: 127-128. 
en peligro esta unidad»; $5^{\mathrm{a}}$, por último, citando expresamente a Sièyes, afirmaba que el Senado en un sistema democrático no tenía sentido, ya que «si las dos Cámaras van unidas y representan la voluntad popular, una sobra; si la otra se opone, entonces no representa la volonté générale, que es lo que debe representar el poder legislativo» ${ }^{75}$.

El discurso de Jiménez de Asúa concluía poniendo de manifiesto el motivo central que había materializado el rechazo al Senado: «No es, pues, posible mantener el viejo Senado, porque si hoy quisiéramos resucitar con el Senado el lugar en donde las excelencias de edad, de cultura o de riqueza estuviesen representadas, estableceríamos un concepto diverso, antiigualitario, incompatible con el sistema democrático; y si lo que se quiere hacer con el Senado es establecer una cámara en donde se resuelvan los conflictos entre el capital y el trabajo, lejos de hallar una solución, se ahondarían más profunda, más fuerte, más insondablemente los antagonismos entre los dos elementos» ${ }^{76}$.

Todos los argumentos empleados por los bicameralistas fueron desmontados sistemáticamente por los partidarios del unicameralismo, a la postre triunfante. Mariano Ruiz Funes (AR), por la Comisión, hizo acopio de razonamientos políticos y técnicos, para llegar al argumento que creía de mayor peso: «el Senado, organismo fundamentalmente conservador, organismo de ritmo lento, puede presentar, frente a la marcha ascendente de la República, un obstáculo insuperable; nosotros hemos querido salvarlo por la vía legal de la Constitución para que no se salvara por el pueblo por la vía ilegal de la revolución $\gg^{77}$. La intervención de Ruiz Funes sirvió de réplica a la de AlcaláZamora. No había motivo, como pretendía el presidente del Gobierno provisional, para buscar una cámara de la continuidad o de la tradición, puesto que nada vinculaba a una Asamblea constituyente que trataba precisamente de reformar el sistema político nacional, empezando por un Senado que tan aciagos recuerdos traía desde la Restauración. Mucho menos debía pretenderse un Senado que tuviese por objeto frenar a la cámara democrática. La propia democracia tenía sus mecanismos de contención, como eran las elecciones, y, por tanto, el sistema remitía a la sanción electoral a los diputados que no hubiesen cumplido fielmente con sus cometidos y se hubiesen excedido ${ }^{78}$.

Finalmente, los razonamientos de Alcalá-Zamora destinados a descargar al presidente de la República del veto suspensivo y evitarle un posible enfrentamiento con el Parlamento sirvieron a Ruiz Funes para cerrar su turno: «¿Por qué estatuir un órgano complejo y costoso? ¿Por qué permitirnos el lujo de pagar tan caro ese veto, cuando puede ejercerse desde el poder presidencial?

\footnotetext{
${ }^{75}$ DSCC, $\mathrm{n}^{\circ} 28$, de 27 de agosto de 1931, p. 646.

${ }^{76} D S C C, \mathrm{n}^{\mathrm{o}} 28$, de 27 de agosto de 1931, p. 646.

${ }^{77}$ DSCC, $\mathrm{n}^{\mathrm{o}}$ 63, de 27 de octubre de 1931, p. 1.957.

${ }^{78}$ DSCC, $\mathrm{n}^{\circ} 63$, de 27 de octubre de 1931, pp. 1.954-1.956.
} 
¿A qué hablar del Senado como organismo rectificador de errores, si todos los órganos del poder tienen medio de rectificarlos? ¿A qué hablar de un organismo que pueda representar exclusivamente la autoridad de la vejez si no hay inconveniente en que a la cámara única vengan jóvenes y viejos? ${ }^{79}$.

El encargado de contraargumentar a Alcalá-Zamora por el PSOE fue Indalecio Prieto. En su intervención, el dirigente socialista se preguntaba una y otra vez: «¿Freno de qué? ¿Contrapeso de qué?». El Senado no se justificaba, a su juicio, para estos menesteres. Recordando otra intervención suya anterior, el propio Prieto advertía de que la República era como un molde, «aunque ese molde había que llenarlo de contenido democrático, y que el peligro más grande que corría la República era que, apoderados determinados elementos del molde republicano, lo volvieran a llenar con todas las heces de la podredumbre caciquil y de la escoria social de España ${ }^{80}$. Ángel Galarza, de la minoría radical-socialista, incidiría en la misma línea. En su opinión, «no necesita la política española y la obra legislativa freno, sino que tenga audacia y estímulo, y la audacia y el estímulo únicamente lo puede encontrar en una sola cámara y ¡ojalá, ésta se sintiera siempre acuciada por el pueblo para encontrar en él la audacia y el estímulo que a veces le falta! Por eso nosotros votamos por una sola cámara $\rangle^{81}$.

Había otro argumento político de fondo para rechazar el Senado. Un argumento conectado directamente con la concepción pluralista y polémica de la vida social, con el reconocimiento de la lucha de clases y el recuerdo constante de la utilización interesada y parcial de las instituciones del Estado por parte de los más privilegiados. Desde este ángulo de visión, la existencia de un Senado - incluso de un Senado corporativo de representación ponderada de todos los grupos, clases y actividades con relevancia social-, representaría un foco de tensión proclive a seccionar y dividir el interés general, y tendente también a producir la parcelación de la representación. Así, Manuel Ruiz de Villa (PRRS), frente al argumento de que era preferible una presencia de los intereses y clases en forma dialogante, antes que éstos tuvieran que actuar desde la clandestinidad, opinaba que «los intereses diferenciados no podrán dar jamás una pauta imperativa del interés general» ${ }^{82}$. También su compañero de filas, Leopoldo García-Alas, participaba de esta opinión, siendo aún más explícito en la idea: «Y se habla de un Senado de corporaciones,

${ }^{79}$ DSCC, ${ }^{\circ}$ 63, de 27 de octubre de 1931, p. 1.957. Leopoldo García-Alas (PRRS) vendría a abundar en el mismo argumento: «Frenos, no. Ya nos frenará la opinión pública. Nosotros no podemos poner frenos; necesitamos un acicate para esta Cámara y para los que la constituyen». Vid. DSCC, $\mathrm{n}^{\circ}$ 62, de 23 de octubre de 1931, p. 1.920.

${ }^{80} D S C C, \mathrm{n}^{\circ} 63$, de 27 de octubre de 1931, p. 1.958.

${ }^{81}$ DSCC, $\mathrm{n}^{\circ} 63$, de 27 de octubre de 1931, p. 1.961.

${ }^{82}$ DSCC, $\mathrm{n}^{\mathrm{o}} 62$, de 23 de octubre de 1931, p. 1.908. 
disfrazado de Cámara corporativa. Es casi peor. El viejo Senado, siquiera representaba algo respetable, como es la tradición; pero ese Senado nuevo representaría algo que no es respetable: los intereses egoístas puestos a legislar. Y eso no. Se legisla a título de ciudadano; pero a título de mercader, de industrial, de profesor, de obrero, no se legisla nunca. De modo que, ni con disfraz, ni sin disfraz, podemos admitir esta segunda cámara» ${ }^{83}$.

Pero donde el tema adquirió perfiles políticos más fuertes fue en la intervención de Ruiz Funes: «¿Ha de ser un Senado que represente estrictamente los altos intereses de la burguesía, como una Cámara de contrapeso, frente al Congreso, cámara de elección popular? Tampoco cabe esto en la República democrática, que afirma ser, además, una República de trabajadores de toda clase. ¿Ha de ser un Senado de tipo corporativo, perfectamente infiltrado de principios fascistas, detrás del cual puede adivinarse la turbia sombra de $\mathrm{Mu}-$ ssolini? Una Constitución democrática no puede aceptarlo» ${ }^{84}$.

Tampoco convencía al sector unicameralista de las Cortes Constituyentes la idea de una cámara corporativa, puesto que, por una parte, se consideraba que acabaría por convertirse en una cámara política más, despreocupada de los intereses de los grupos sociales que representaba y más ocupada de tomar parte en la vida política general. Pedro Armasa (PRR) veía en este Senado corporativo el riesgo de que se tornase en el refugio del caciquismo, una vez que éste se hubiese desarraigado de la Cámara Baja a través de una reforma electoral profunda, basada en el sufragio universal ${ }^{85}$. Finalmente, el argumento a favor de la investidura del presidente de la República tampoco se consideró suficiente ${ }^{86}$, de forma que se barajaron otras alternativas. Así, Ortega y Gasset (ASR) consideraba que esta elección debía correr a cargo de los Par-

${ }^{83}$ DSCC, $\mathrm{n}^{\mathrm{o}} 62$, de 23 de octubre de 1931, p. 1.920.

${ }^{84}$ DSCC, $\mathrm{n}^{\mathrm{o}}$ 63, de 27 de octubre de 1931, p. 1.955. A estas afirmaciones sucedieron interrupciones y protestas de Alcalá-Zamora y de otros diputados bicameralistas, que ponen de relieve el clima crispado en que se desenvolvió la discusión del tema de la estructura de las Cortes.

${ }^{85}$ DSCC, $\mathrm{n}^{\mathrm{0}}$ 63, de 27 de octubre de 1931, p. 1.961.

${ }^{86}$ En cuanto a la elección presidencial, la Constitución de la Segunda República estableció un sistema indirecto, de segundo grado, según el cual se formaría un colegio electoral compuesto por el Congreso de los Diputados y un número de compromisarios, elegidos por sufragio universal, igual al de diputados (art. 68). Sin embargo, hasta llegar a la solución finalmente alumbrada por el texto constitucional hubo que recorrer un complicado trecho. En primer lugar, la comisión jurídica asesora había dispuesto en el anteproyecto (art. 52) unas Cortes bicamerales, de forma que, siguiendo el método de la Tercera República francesa, al presidente de la República lo elegirían ambas cámaras, Congreso y Senado, reunidas en Asamblea Nacional. Más tarde, el proyecto aprobado por la comisión de constitución suprimió el Senado y viró ostensiblemente hacia el modelo de la República de Weimar, estableciendo para la elección el sufragio universal y directo (art. 66). Vid. JULIÁ, 2009: 13-86, y GIMÉNEZ MARTÍNEZ, 13 (Madrid, 2015): 66-67. 
lamentos regionales ${ }^{87} \mathrm{o}$, como proponía Luis Fernández Clérigo (AR), concurriendo a las Cortes los representantes de los municipios para proceder a la mencionada elección ${ }^{88}$.

Las posturas más combativas consideraron que el Senado nunca podría desprenderse de su halo de "Cámara de clase», conservadora y antirrevolucionaria, tanto más innecesaria precisamente en un momento de revolución política. Los había también que, sin obedecer a planteamientos partidistas, se alzaban desde consideraciones generales hechas a partir de la observación de la realidad histórica circundante y la reflexión acerca de las tendencias humanas. Este es el caso de José Ortega y Gasset. Aunque reconocía la representación de intereses en la teoría, «esta idea feliz no ha podido nunca realizarse, y en la reciente Constitución de Weimar, cuando se creó el Consejo Económico del Reich, se quiso algo parecido una vez más ${ }^{89}$; pero es un hecho que ya a estas alturas ese Consejo no funciona y ha sido uno de los fracasos con que cuenta esa Constitución». Pero es que, además, para Ortega la idea de una segunda cámara no se sostenía. Si no se le otorgaban «carácter y atributos políticos», sería «una Cámara castrada». Pero si se le concedía tal perfil, al poco tiempo «de corporativa se convertirá [...] en pura Cámara política, tan popular como la otra y tan apasionada. Lo corporativo no resiste el vigor de las ideas y de la pasión política: la política en la Historia, señores, es el macho» ${ }^{90}$. Indalecio Prieto seguiría en parte este razonamiento al indicar, poco después, que «crear esa cámara de intereses, por la cual tanto se aboga, de representación corporativa y que ha de ser forzosamente una cámara política, es tanto como llevar la pasión, la discordia, la santa discordia política, al seno de las corporaciones que tienen misión social muy distinta que cumplir; es decir, sería envenenar la esfera serena en que deben desenvolver su actividad corporaciones de índole científica, con estas luchas de la política que les son ajenas $\rangle^{91}$.

Por su parte, el radical-socialista Manuel Ruiz de Villa atacaría la justificación bicameralista hecha por los federales: «En toda esta cuestión del sistema bicameral, otra cosa sería si España hubiera adoptado la estructura de un Estado federal. Entonces, sí, era necesaria la segunda cámara [...] Ahora bien, yo no niego la posibilidad de que el gesto federable estampado en nuestra Constitución nos lleve, nos arrastre, a una Federación, pero lo que no se puede hacer en materia constitucional, como en mecánica, es crear unas piezas que puedan tener una posible utilización en el porvenir». Y es que, en lo refe-

${ }^{87}$ DSCC, $\mathrm{n}^{\circ} 33$, de 4 de septiembre de 1931, p. 777.

${ }^{88}$ DSCC, $\mathrm{n}^{\circ}$ 62, de 23 de octubre de 1931, p. 1.915.

${ }^{89}$ Sobre el art. 165 de la Constitución de Weimar y el Reichswirtschaftsrat, vid. BÜHLER, 1931: 81 y ss.

${ }^{90}$ DSCC, $\mathrm{n}^{\mathrm{o}} 33$, de 4 de septiembre de 1931, p. 778.

${ }^{91} D S C C, \mathrm{n}^{\circ} 63$, de 27 de octubre de 1931, p. 1.963. 
rente a la parte orgánica, «no se pueden crear sino aquellos organismos que vayan a ser utilizados a impulso de vivas necesidades» ${ }^{92}$.

El sector partidario de una Cámara única se mostró muy celoso del predominio institucional del Congreso ${ }^{93}$ y reaccionó al catastrofismo mostrado por el otro bloque de opinión aduciendo que el verdadero peligro para la prosecución de la revolución política iniciada era la permanencia misma del Senado. Galarza (PRRS) invirtió el juicio de Alcalá-Zamora al decir que en la existencia del Senado «va el porvenir de la República, pero precisamente desde el otro lado de la barricada». Más allá de la composición que se le quisiera dar, el Senado se convertiría «en una covachuela de la reacción y allí existirían los cómplices de una pretendida restauración $\gg{ }^{94}$. Minutos antes, Indalecio Prieto había tratado de deshacer la impresión temerosa que las palabras de AlcaláZamora hubieran podido dejar en el hemiciclo. Se había hablado de «graves peligros» y pareciera como si se cerniera sobre la Cámara, «siempre siniestra, el panorama de una guerra civil». "Yo nunca he creído en ella», añadió el líder socialista. "Yo nunca he temido ese peligro», dijo más adelante refiriéndose al fanatismo religioso puesto contra la República, «ni lo temo, pero temo al peligro de lo que yo llamo — perdonadme la frase - la traición interna a la República, un desdibujamiento total, una decepción en las masas, un fraude republicano, y en el camino del fraude hacer una República conservadora, tímida, reaccionaria, negativa de todos los sinceros avances democráticos y de todos los progresos sociales, en este camino del fraude de la deformación y de la traición interna de la República es un paso considerable la creación de un Senado, que, cualquiera que fuese su estructura, no serviría sino para dificultar, para entorpecer y, a veces, para traicionar los designios de la democracia española, plasmada en el sufragio universal y representada aquí por los diputados, en la única Cámara que tiene plena legitimidad en una democracia, honda, seria y honradamente sentida» ${ }^{95}$.

Generalmente, las objeciones dirigidas a la representación corporativa se mantuvieron dentro de la línea doctrinal, sin entrar en alegatos políticos de fondo; quizá porque el corporativismo era un fenómeno todavía reciente y no había sido puesto aún plenamente en práctica en los Estados totalitarios europeos, quizá porque en la defensa de la representación corporativa concurrieron figuras no vinculadas a movimientos reaccionarios o conservadores, como es el caso de los antes mencionados Fernando de los Ríos y Julián Besteiro. De un lado se insistía en que el corporativismo y una representación

${ }^{92}$ DSCC, $\mathrm{n}^{\mathrm{o}}$ 62, de 23 de octubre de 1931, p. 1.908.

93 GUILLERM, 1933: 69, creía, en este sentido, que las Cortes Constituyentes eludieron todo «freno a la acción de las futuras Cortes o Parlamento».

${ }^{94}$ DSCC, $\mathrm{n}^{\mathrm{o}}$ 63, de 27 de octubre de 1931, p. 1.961.

${ }^{95} D S C C, \mathrm{n}^{\mathrm{o}}$ 63, de 27 de octubre de 1931, p. 1.960. 
política inspirada por éste requerían unas condiciones previas, un tejido asociativo aportado por la sociedad que España no estaba en condiciones de proporcionar. Por otra parte, existía en muchos diputados el temor a que, a la larga, la representación política de los intereses particulares terminara subvirtiendo el mecanismo representativo del que emanaba de forma espontánea el interés general. Es el caso, por ejemplo, del radical-socialista Emilio Baeza, quien alertó de las posibles corruptelas que podían suplir la falta de auténticas asociaciones y corporaciones, «muchas de las cuales ya sabemos a qué deben su origen, a aprovecharse caciquilmente de una falta de vida corporativa en España, para que resulten representantes de entidades y corporaciones los que en la realidad no representan a corporaciones ni entidades, o representantes de clases que, en definitiva, anteponen al interés general de la nación la defensa de la clase o la defensa del interés particular, que debe estar pospuesto cuando se viene aquí a promulgar leyes» $\rangle^{96}$.

Aún había quien, además de lo anterior, consideraba difícil la puesta en práctica de tales ideales, que generaba esperanzas poco realistas en el comportamiento de esos órganos sociales. En este sentido, Luis Fernández Clérigo (AR) consideraba que «algo análogo ocurre en los colegios profesionales, porque la corporación no es tampoco exclusivamente la defensa de intereses de clase; la corporación tiene un espíritu disciplinario, y yo estoy seguro de que la mayoría de los que pertenecemos a los colegios profesionales, si examinamos nuestra conciencia, veremos que al lado del espíritu defensivo de clase, el espíritu disciplinario, eso que constituye la verdadera esencia y el nervio de la corporación, está ausente en dichos centros $\rangle^{97}$.

Hay que decir, sin embargo, que entre los constituyentes de 1931 contrarios al bipartidismo como expresión de la representación de intereses no se había desarrollado todavía una crítica al corporativismo en tanto doctrina relacionada con el fascismo. Félix Gordón Ordás (PRRS) es tal vez el diputado que se acercó más decididamente a este problema, que todavía no se había revelado con claridad: la utilización por los movimientos autoritarios y totalitarios en alza del corporativismo. A su juicio, parecía evidente «que los individuos tienen que ir cediendo voluntariamente parte de sus derechos para integrar los Estados fuertes modernos; pero esto no quiere decir que los derechos del individuo no sean lo primero a reconocer». Esta especie de contradicción no era tal, de modo que «es absolutamente injustificada la oposición que se cree existe entre el Estado individual y el Estado corporativo. El criterio nacido en el fascismo de que el Estado corporativo es contrario a las libertades individuales no tiene fundamento lógico ni razón ninguna de ser» ${ }^{98}$.

${ }^{96}$ DSCC, $\mathrm{n}^{\circ} 65$, de 29 de octubre de 1931, pp. 2.027-2.028.

${ }^{97}$ DSCC, $\mathrm{n}^{\circ} 62$, de 23 de octubre de 1931, p. 1.914.

${ }^{98}$ DSCC, $\mathrm{n}^{\mathrm{o}} 42$, de 22 de septiembre de 1931, pp. 1.047-1.048. 


\section{LOS CONSEJOS TÉCNICOS: UNA ALTERNATIVA FRUSTRADA}

Pese a todas las argumentaciones y matizaciones, en las Cortes Constituyentes de 1931 no hubo lugar para un bicameralismo que institucionalizara la representación de intereses en una segunda cámara. Lo único que se podía intentar era salvar algunas de las ventajas que se pretendían con el organicismo. De aquí vino la solución de los Consejos Técnicos, resultantes de la transacción a que se llegó en el seno de la Comisión de Constitución, reflejo también de los acuerdos en el seno del grupo parlamentario socialista, y que significó para algunos ${ }^{99}$ la alternativa a la Cámara corporativa que se había demostrado inviable en el debate entablado en el Pleno.

Aunque los Consejos Técnicos estaban ya previstos en el ACRE, con la potestad de emitir dictámenes sobre «los proyectos y los decretos de carácter general» y de redactar proposiciones de ley ${ }^{100}$, en el PCRE recibieron un tratamiento más detallado, a instancias del voto particular que Matilde Huici y varios vocales de la comisión jurídica asesora formularon proponiendo un Título VI bis. La Comisión parlamentaria, recogiendo esta última iniciativa, redactó un Título VII que comprendía tres artículos y señalaba la necesidad (supeditada a lo que estableciera una ley ulterior de desarrollo) de establecer Consejos Técnicos autónomos, con funciones de examinar «toda medida de importancia [...] antes de ser presentada a la aprobación del Congreso» y de redactar «un proyecto de ley o un reglamento» 101 a instancias del Gobierno. A semejanza del ACRE, el PCRE facultaba al Congreso para confiar a un consejo técnico «la preparación de una determinada ley, que servirá de base a los trabajos de la Comisión parlamentaria correspondiente» ${ }^{102}$.

Cuando Jiménez de Asúa presentó el PCRE hizo hincapié en la línea divisoria existente entre las pretensiones senatoriales desechadas y la «novedad» de los Consejos Técnicos. Se debían éstos al convencimiento de que «la democracia no es enemiga de la técnica», y a la intención de rendir tributo de respeto a la comisión jurídica asesora, pues la labor de ésta «ha sido principalmente el estímulo para crear estos Consejos, los Consejos Técnicos, inseparables de un buen sistema unicameral». Pese a que estos Consejos «están hoy en embrión», serían en lo porvenir «interesantes capítulos del Derecho Público, y no pasará a él la vieja savia del Senado, sino, por el contrario, el poder de reflexión que se quiere buscar en otras segundas cámaras» ${ }^{103}$.

99 PÉREZ SERRANO, 1932: 282-285; ROYO-VILLANOVA, 1934: 273 y ss.

${ }^{100} A C R E$, art. 44.

101 PCRE, art. 93.

102 PCRE, art. 94.

${ }^{103}$ DSCC, $\mathrm{n}^{\mathrm{o}} 28$, de 27 de agosto de 1931, p. 647. Sobre el problema de los Consejos Técnicos en la etapa constituyente, vid. JIMÉNEZ DE ASÚA, 1932: 393-400. 
La creación de los Consejos Técnicos se debió fundamentalmente a la iniciativa de Fernando de los Ríos, que veía en ellos el medio de resolver «la pugna entre democracia y competencia ${ }^{104}$. De los Ríos ponderaba la necesidad de los organismos técnicos asesores como garantía de la democracia, "porque la democracia sin ciencia que la acompañe es un personaje titular de incompetencia, y a causa de la necesidad de que la democracia sea eficiente, se precisa que entre la opinión pública y el órgano parlamentario o el Gobierno, órganos decisorios, aparezca el órgano asesor, dotado de una competencia específica en el problema concreto sobre el cual haya de conocer Parlamento o Gobierno» ${ }^{105}$.

Fernando de los Ríos trajo a colación, además del Consejo Económico alemán, las Comisiones inglesas, y adujo la necesidad imperiosa de este tipo de organismos si, como se demandaba por algunos grupos con insistencia creciente (y muy particularmente en el seno de su propio partido), se había de ir a una progresiva planificación de la economía. Con todo, esos organismos de asesoramiento y consulta, no decisorios, se formarían «en razón de su competencia, articulados verticalmente, desde el elemento vital social, el Sindicato profesional y Sindicato obrero, hasta la plena objetividad científica, representada por el experto y el técnico, que pudieran en todo instante facultar la obra del Gobierno y modificar la manera de actuar del Parlamento» ${ }^{106}$.

La aceptación de estas pretensiones se reveló harto complicada por la falta de apoyos que cosechó en la Cámara ${ }^{107}$. Los diputados que habían luchado por la consecución de un Senado y por la representación orgánica no se resignaron a aceptar lo que consideraban una fórmula rebajada que no satisfacía sus aspiraciones. Carlos Blanco (PRP) habló de la «exuberancia del tecnicismo» que se podía producir, porque «el Congreso y el Senado (nosotros somos partidarios de él en la forma que he indicado), y además las Comisiones parlamentarias y el Consejo de Estado y también todos los centros que existen en los departamentos ministeriales, por necesidad técnicos, para asesorar a los ministros y preocuparse de la elaboración de las leyes desde el momento que se conciben; todo esto nos parece tecnicismo bastante para que pongamos sobre este tecnicismo otro, el de los Consejos llamados así, técnicos» ${ }^{108}$. Por otro lado, jugaba negativamente la prevención que suscitaban los «técnicos»y

${ }^{104}$ DSCC, n $^{\text {3 } 32, ~ d e ~} 3$ de noviembre de 1931, p. 752. Fernando de los Ríos había evolucionado desde un bicameralismo en sentido corporativo, similar al de Julián Besteiro, hasta los Consejos Técnicos. Vid. ZAPATERO, 1974: 206-211.

${ }^{105}$ DSCC, $\mathrm{n}^{\circ} 71$, de 10 de noviembre de 1931, p. 2.224.

${ }^{106}$ DSCC, $\mathrm{n}^{\mathrm{o}} 71$, de 10 de noviembre de 1931, p. 2.224 .

${ }^{107}$ Apenas cabe contar entre los defensores del sistema propuesto por Fernando de los Ríos al canónigo Ricardo Gómez Rojí, diputado agrario por Burgos. Vid. DSCC, $\mathrm{n}^{\circ} 33$, de 4 de septiembre de 1931, pp. 764-771.

${ }^{108}$ DSCC, n $^{\circ} 31$, de 2 de septiembre de 1931, pp. 731-732. 
su posible influencia sobre los «políticos», e incluso la suplantación de éstos por aquéllos, apoyados en la fuerza de sus conocimientos específicos ${ }^{109}$. Por último, pesó de manera decisiva la sospecha de que se pretendía introducir, algo subrepticiamente, un bicameralismo y un organicismo que habían sido impugnados sin duda alguna ${ }^{110}$.

Así pues, quedó rechazado no solo el Senado, sino también cualquier otro sucedáneo como los Consejos Técnicos: la Cámara aprobaría por 136 votos contra 109 una enmienda del federal Manuel Ayuso que los suprimía, y solamente, gracias a una nueva intervención de Fernando de los Ríos, se recogería en el artículo 93 de la Constitución la vaga posibilidad de crear «órganos asesores y de ordenación económica de la Administración, del Gobierno y de las Cortes» ${ }^{11}$.

Finalmente, al abordarse el tema del Tribunal de Garantías Constitucionales, se produciría una última tentativa por introducir el Senado en la Constitución. A juicio de varios diputados, Alcalá-Zamora entre ellos, la distribución de funciones que hacía la Constitución entre la Presidencia de la República y las Cortes podía resultar peligrosa, pues, como consecuencia de la supresión del Senado, «el poder del presidente de la República, o es ilusorio o es incontrastable, o inútil o peligroso» ${ }^{112}$. Se precisaba, por tanto, un órgano que amortiguara los roces entre el presidente y las Cortes, evitando un posible enfrentamiento. Y si el Senado había quedado descartado ya, ante la oposición irreductible de una mayoría de diputados, había que ir a otro mecanismo que cumpliera esta función.

Con esta intención, parlamentarios que anteriormente habían sido defensores del Senado volvieron sobre la idea de la necesidad de un órgano con misión parcial de asesoramiento y asistencia del presidente. En efecto, ya muy avanzada la elaboración de la Constitución, mientras se discutía el Título IX, relativo al Tribunal de Garantías Constitucionales, una enmienda de Gabriel Franco (AR), que se unió a otra de José Xirau (USC), vino a insistir en la idea de que «falta una pieza en este mecanismo que sirva como de amortiguador en los conflictos que puedan surgir entre el presidente de la República y la Cámara» ${ }^{113}$. Se propuso, de esta forma, la creación de un «Consejo de la Re-

${ }^{109}$ En este sentido, cabe destacar la intervención del diputado de Unió Socialista de Catalunya (USC), Gabriel Alomar. Vid. DSCC, $\mathrm{n}^{\mathrm{o}}$ 72, de 11 de noviembre de 1931, p. 2.227.

${ }^{110}$ Los esfuerzos de Niceto Alcalá-Zamora por diferenciar el Senado de los Consejos Técnicos (DSCC, n ${ }^{\circ}$ 63, de 27 de octubre de 1931, p. 1.951) o las llamadas de atención de Juan Castrillo para hacer ver la confusión que se estaba creando en torno al tema discutido, causada en parte por la pasión partidista $\left(D S C C, \mathrm{n}^{\circ} 71\right.$, de 10 de noviembre de 1931, p. 2.235), no sirvieron de nada.

${ }^{111}$ DSCC, $\mathrm{n}^{\mathrm{0}} 71$, de 10 de noviembre de 1931, p. 2.236.

${ }^{112}$ DSCC, $\mathrm{n}^{\circ} 63$, de 27 de octubre de 1931, p. 1.952.

${ }^{113}$ DSCC, $\mathrm{n}^{\mathrm{o}} 81$, de 26 de noviembre de 1931, p. 2.648. 
pública», «como un amortiguador entre los poderes de la Cámara, por una parte, y los poderes del presidente, por otra» ${ }^{114}$. En este órgano podría apoyarse el presidente para ejercer el veto legislativo, y a este órgano habría de oír antes de proceder a disolver las Cortes. Las atribuciones que se pensaba debía cubrir este organismo eran muy variadas. No sería solamente un órgano de asesoramiento del presidente en momentos especialmente delicados. Se trataba al mismo tiempo de instituirlo en alto tribunal que conociera no solo la inconstitucionalidad de las acciones y normas, sino incluso de los conflictos interorgánicos y de los surgidos entre las diversas instancias de poder territorial, aparte juzgar las causas criminales dirigidas contra los titulares de las funciones más elevadas del Estado.

La reacción ante tales pretensiones no se hizo esperar. Jerónimo Gomáriz (PRRS) volvió a sacar a relucir el «fantasma» senatorial: «¿Es o no cierto, señores federales, que esto que se propone es un Senado?», previno. Siendo así, no se le debía prestar atención entonces, «ya que, se trata de un Senado más o menos atenuado, y no debemos volver sobre un acuerdo que hemos adoptado» ${ }^{115}$. A esta alusión contestó Bernardino Valle (PRDF) con sinceridad: «lo que hoy se debate, por nuestra parte [de los federales], es rescatar un Senado que consideramos absolutamente indispensable para el juego de los poderes de la República» ${ }^{116}$.

Esta vez, llegada la votación de la enmienda, la diferencia fue mucho más ajustada que en otras ocasiones, siendo rechazada la propuesta por 144 votos en contra y 135 a favor ${ }^{117}$. Otros votos particulares y enmiendas se consideraron por sus firmantes afectados por la precedente votación, de manera que fueron retirados en un clima de pesimismo general de los bicamaralistas, excepción hecha de Royo-Villanova, que no quiso abstenerse de hablar «por razón que han expuesto estos señores de estar ya prejuzgada la cuestión» ${ }^{118}$.

En este desenlace negativo influyó, a juicio de Nicolás Pérez Serrano, el hecho de que «los Consejos propuestos no podían ser un sustitutivo del Senado, porque su pluralidad los hacía estériles; y no servían para corregir la incompetencia democrática, porque toda pericia impuesta resulta mortificante, y porque hay otros medios de hacer que las Cámaras actúen con elementos expertos. Además, era inadmisible que en la parte orgánica de una Constitución se estableciera como institución nueva lo que no pasaba de ser la estruc-

${ }^{114}$ DSCC, $\mathrm{n}^{\mathrm{o}} 81$, de 26 de noviembre de 1931, p. 2.656.

${ }^{115}$ DSCC, $\mathrm{n}^{\circ} 81$, de 26 de noviembre de 1931, p. 2.651.

${ }^{116}$ DSCC, $\mathrm{n}^{\mathrm{o}} 81$, de 26 de noviembre de 1931, p. 2.651.

${ }_{117}$ DSCC, $\mathrm{n}^{\circ} 81$, de 26 de noviembre de 1931, p. 2.658.

${ }^{118}$ DSCC, $\mathrm{n}^{\circ} 81$, de 26 de noviembre de 1931, p. 2.667. 
tura espectral de un fantasma mal urdido; y parecía pueril querer reemplazar el Senado único con unas lamentables caricaturas de senadillos» ${ }^{119}$.

Aquellos que fiaban mucho en la oportunidad de dar cabida a la corriente organicista fueron igualmente críticos con la decisión de las Cortes Constituyentes de 1931. «Es de lamentar que las Cortes españolas de la Segunda República», escribía Adolfo Posada tres años después, «no hayan querido considerar la realidad nacional sobre la que debería sentarse el Estado oficial del nuevo régimen. No se dieron cuenta los constituyentes del momento en que actuaban, tan lejano históricamente de 1789, tan impropio para expansiones de jacobinos, y tan oportuno, en cambio, para intentar introducir en la Constitución política la representación específica de los intereses sociales organizados, creando al lado de la Cámara popular, representativa del conjunto numérico y del asiento geográfico de los ciudadanos, una Cámara sindical representativa de aquellos intereses, Cámara que ya echan de menos algunas gentes, incluso los que impidieron que la Constitución de 1931 fuera hoy un argumento vivo que oponer a la crítica fascista» ${ }^{120}$.

\section{EL PROYECTO DE REFORMA CONSTITUCIONAL DE 1935}

La idea de la necesidad de una reforma de la Constitución surgió muy tempranamente entre los que se habían negado a aceptar el texto e incluso habían anunciado el propósito de trabajar por su inmediata revisión. Recordemos con qué énfasis agrarios y vasco-navarros habían manifestado su repudio, con abandono del salón de sesiones, en la oportunidad de los debates sobre congregaciones religiosas y confesionalidad del Estado, y las dimisiones de Alcalá-Zamora y Miguel Maura ${ }^{121}$, de sus cargos en el Gobierno, por igual motivo. La oportunidad les fue deparada por las elecciones de 1933, con las que tomaron asiento en el hemiciclo un buen número de cuantos, desde 1931, venían clamando por un cambio constitucional. El Gobierno que presidía Alejandro Lerroux hizo suya esta ambición pero, acuciado por otros problemas y temeroso de las posibles reacciones, necesitó del apoyo y la iniciativa del propio Alcalá-Zamora, «quien, de manera oficiosa, pero conocida, asumió y

119 PÉREZ SERRANO, 1932: 284-285. Alcalá-Zamora decía, por ello, que tal sustitución era tan absurda como lo sería el caso de un señor que marchara descalzo por la calle, y al preguntarle alguien la razón de su extraño proceder argumentara alegando que llevaba enguantadas las manos. Vid. DSCC, $\mathrm{n}^{\mathrm{o}} 63$, de 27 de octubre de 1931, p. 1.951.

${ }^{120}$ POSADA, 1934: 166.

${ }^{121} \mathrm{La}$ resolución de la crisis ministerial subsiguiente puede verse en $D S C C, \mathrm{n}^{\mathrm{o}} 56$, de 14 de octubre de 1931, pp. 1.723-1.729. 
activó la política revisionista, apropiándose, de algún modo, de una iniciativa que la Constitución atribuía al Gobierno» ${ }^{122}$.

Así, se advierte una similitud de propósitos entre el proyecto que fue leído ante las Cortes por Lerroux ${ }^{123}$, y las ideas defendidas como imprescindibles para reencauzar la República, retocando la Constitución, expuestas por Alcalá-Zamora. En cuanto al tema que nos ocupa, el proyecto contenía una exposición de motivos que incluía un apartado de denuncias al funcionamiento de la Constitución de 1931, una de las cuales hacía alusión a los «abusos en la iniciativa parlamentaria de las leyes. La instauración del Senado es la única solución conocida. Las bases de su organización, funcionamiento y atribuciones deberán figurar en la futura Constitución reformada» ${ }^{124}$.

El proyecto de reforma constitucional de 1935 intentó resolver el conflicto de la Cámara única. De esta suerte, relacionando la existencia de una segunda cámara con la elección presidencial - como si se tratara de proseguir la discusión parlamentaria en el punto en que había quedado en las Constituyentes-, se decía que «los compromisarios deberán desaparecer ${ }^{125}$ y ser sustituidos por el Senado, si éste se instaura, en la hipótesis de que las Cortes Constituyentes no prefieran otro sistema de elección presidencial». «Reformado este artículo (el 68), la modificación se reflejará necesariamente en el artículo 82. De establecerse el Senado, la Vicepresidencia de la República parece que habría de corresponder al Presidente de aquella cámara, en armonía con lo que es el principio y práctica generalmente admitida».

Uno de los principales objetivos del proyecto de reforma era infundir al poder público estabilidad y vigor, para lo que se delineó una nueva distribución, que se reputaba más equilibrada, de poderes. En primer lugar, se pretendía rebajar el poder de las Cortes con la instauración, reclamada como necesaria tantas veces, de un Senado orgánico de reflexión. El Senado atraería hacia sí parte de los cometidos de otros órganos, especialmente del Tribunal de Garantías Constitucionales, que, como anunciaba la exposición de motivos del

122 TOMÁS VILLARROYA, 2 (Valencia, 1976): 20.

${ }^{123}$ Diario de las Sesiones de las Cortes (DSC), n 218 , de 5 de julio de 1935, p. 8.900.

${ }^{124} \mathrm{El}$ texto del proyecto de reforma constitucional se puede consultar en $D S C$, ap. $4^{\circ}$ al $n^{\circ}$ 218, de 5 de julio de 1935 .

${ }^{125} \mathrm{El}$ art. 52 del ACRE preveía que el presidente de la República fuera elegido por «el Congreso y el Senado reunidos en Asamblea nacional». Al eliminar el Senado, el PCRE (art. 66) trató de compensar la falta de contrapeso parlamentario al Congreso e introdujo la elección por sufragio directo y universal de los ciudadanos. Finalmente, la CRE (art. 68), «temiendo el sistema plebiscitario» (ARBELOA MURU, 1977: 53) optaría por un sistema indirecto, de segundo grado, según el cual se formaría un colegio electoral compuesto por el Congreso de los Diputados y un número de compromisarios, elegidos por sufragio universal, igual al de diputados. Vid. sobre este particular JIMÉNEZ DE ASÚA, 1946: 46. 
proyecto, «podía quedar disminuido o eliminado» ${ }^{126}$. Ahora bien, el elemento más relevante en la configuración política del Senado no era la asunción de las funciones predichas, sino las atribuciones de fiscalización que habría de asumir, invadiendo la esfera de poder del Congreso de los Diputados. El Senado proyectado en 1935 no sería, por tanto, solo un «parachoques», como daba a entender la exposición de motivos, sino que quedaría configurado como una segunda cámara con auténtico poder político. En efecto, la exposición de motivos refería que «caso de establecerse el Senado, en lo que se refiere a la responsabilidad política de los ministros, podría tener función fiscalizadora y hasta potestad de emitir votos de censura» ${ }^{127}$. Sobrepasaba, así pues, el planteamiento de los bicameralistas en los debates de las Constituyentes de 1931, que con frecuencia hacían ver que la segunda cámara en nada mermaría las facultades políticas privativas del Congreso, al que se confiaba la misión fiscalizadora de la actividad gubernamental ${ }^{128}$.

De cualquier manera, los Gobiernos del bienio derechista no se atrevieron a seguir con el empeño de la reforma, lo que, desde luego, es explicable. Por un lado, la reacción política de la izquierda, caso de que se hubiera persistido con ella, no se habría hecho esperar. Aun a sabiendas del poco entusiasmo del Gobierno y de la inapetencia de las Comisiones parlamentarias por el tema, preparativos hubo y precauciones por parte de los grupos de la izquierda parlamentaria, particularmente visible en el eje formado por Azaña ${ }^{129}$ y Prieto ${ }^{130}$, para defender la intangibilidad del texto de 1931. Por lo que respecta a la de-

${ }^{126}$ La Constitución de 1931 llevó al Tribunal de Garantías Constitucionales unos vocales regionales cuyo perfil «era más de senador que de magistrado» (con carácter electivo y sin exigencia de ser juristas) y le otorgó función de alto tribunal para exigir la responsabilidad criminal del presidente y los ministros de la República tras la acusación del Congreso. Así, en el centro de una posible contienda entre el presidente y la Cámara única, en lugar de un Senado mediador, se situaba el Tribunal de Garantías, cuya decisión tendría como consecuencia la destitución presidencial o la disolución de la Cámara. Sobre las consecuencias de la supresión del Senado en el Tribunal de Garantías Constitucionales, vid. RUIZ LAPEÑA, 1982: 44.

127 Por eso, CASTRILLO SANTOS, 1935: 161, pensaba que, tal y como se configuraba el Senado en la reforma constitucional, «compartirá la función política con el Congreso. Y aun a costa del Congreso. Tendrá potestad jurisdiccional a costa del Tribunal de Garantías Constitucionales»».

${ }^{128}$ Sobre el tema de las responsabilidades y el sistema de las dos confianzas en la Segunda República, vid. BAR CENDÓN, 12 (Madrid, 1981-1982): 85-104, y TOMÁS VILLARROYA, 31-32 (Madrid, 1983): 71-100.

${ }^{129}$ En su discurso en el Campo de Comillas de Madrid, el 20 de octubre de 1935, Azaña declaraba que no le importaban tanto «los defectos orgánicos de la Constitución de la República; lo que me importa es su valor, y no ciertamente porque sea obra de nuestro partido ni de ningún partido». Cit. en AZAÑA, 1968, vol. 4: 270-271.

${ }^{130}$ MALEFAKIS, en el prólogo a la edición de los discursos de PRIETO, 1975, llamaba la atención sobre la predisposición del político vasco hacia la defensa de los valores liberalparlamentarios, lo que lo situaba, por su actitud y pensamiento, en una línea socialdemócrata. 
recha, ésta había ganado confianza y organización al tiempo que se había radicalizado frente al sistema político imperante. Una nueva derecha cada vez más seducida por los fascismos europeos, que hacía gala de desacato al espíritu y la forma de la República democrática parlamentaria ${ }^{131}$, régimen político que se denunciaba como inadecuado a las condiciones de la España de los años treinta, por lo que «ni siquiera se hubiera conformado, seguramente, con el proyecto presentado a las Cortes en $1935 »^{132}$.

\section{CONCLUSIONES}

Sobre la pervivencia o no del Senado se vertieron en 1931 y los años inmediatamente posteriores todo tipo de argumentos, pero, sin duda, los que al cabo del tiempo han logrado pervivir, los que aún hoy se nos muestran más evocadores, proceden de aquellos que recelaban de la Cámara única como fuente de inestabilidad y movimientos convulsos. La ausencia de Senado era para muchos un polo de atracción catastrofista. Ya hemos visto cómo AlcaláZamora sostenía - y desde él otros muchos, tanto para reforzar su argumentación como para contradecirla-, que en la existencia o inexistencia de una segunda cámara iba el porvenir de la República. En opinión de Salvador de Madariaga, «al prescindir de una segunda cámara, como algunos de nosotros argüimos en vano en los pasillos y el tiempo demostró, la República arrojó por la ventana una de las más seguras garantías contra los violentos movimientos de opinión que en desenfrenada oscilación pendular iba a desencajarla y derrumbarla» ${ }^{133}$.

Sin embargo, desde la perspectiva actual resulta muy difícil evaluar con objetividad la validez de tales críticas. Es imposible saber en qué medida una segunda cámara hubiera podido modificar, en general, el ritmo político de la Segunda República y, en concreto, determinadas decisiones parlamentarias. De igual forma, no se puede saber si con el Senado hubieran variado en algo los destinos del régimen republicano. La mayor dificultad estriba en que, a pesar de la abundante bibliografía hoy existente, los historiadores y constitucionalistas que se han especializado en la cuestión no han avanzado sobre el tema mucho más allá de las instituciones, y, así, cuando se trata de valorar lo que puede suponer la ausencia del Senado para un sistema político, descubrimos un vacío de elementos de juicio suficientemente sólidos.

${ }^{131}$ Nos remitimos en este punto a las aportaciones de MONTERO GIBERT, 1977, vol. 2: 638-640; TUSELL, 1986, vol. 1: 355 y ss., y ALVAREZ TARDÍO, 2011: 341-418. Desde la perspectiva de las posiciones parlamentarias adoptadas por estos grupos ante los planes de modernización del país, RAMÍREZ JIMÉNEZ, 1977.

132 GARCÍA CANALES, 1977: 288.

${ }^{133}$ MADARIAGA, 1955: 468. 
No se puede asegurar, por tanto, que el cambio de una decisión o norma parlamentaria por parte de una segunda cámara represente una garantía de moderación, de mayor reflexión o preparación técnica de la medida en cuestión. De la misma forma puede replicarse, por ejemplo, que la intervención de esta segunda instancia parlamentaria correría el riesgo de aumentar la complejidad en la tramitación legislativa, disminuyendo la coherencia interna de las leyes y retardando la vigencia de algunas disposiciones especialmente urgentes cuando se trata de llevar a cabo, como era el propósito del régimen republicano, un amplio proceso de renovación social. El valor de contrapeso y compensación de las segundas cámaras es algo, en definitiva, que se encuentra en el campo de las hipótesis más que en el de las realidades confirmadas, y los argumentos, técnicos o funcionales, que se emplean a favor o en contra del bicameralismo no tienen más fuerza que la proporcionada por los razonamientos ideológicos de los que realmente provienen. Es precisamente el análisis de estos últimos lo que permite comprender los cambios que puede experimentar un sistema político mediante la introducción del bicameralismo.

Hay que atenerse a los hechos constatables, no a la cabalística resultante de establecer una relación inmediata y directa entre el número de cámaras parlamentarias y los resultados legislativos. El bicameralismo supone, evidentemente, dar cabida en el sistema a un tipo más de representación parlamentaria. Pero cuando se defiende la idea de una segunda cámara no es, en definitiva, más que porque se considera que existen determinados intereses - territoriales, sociales, económicos, sindicales, corporativos, culturales, etc.-, a los que resulta conveniente dotar de una representación autónoma, separada de la estrictamente individual, con un cierto protagonismo en las decisiones políticas ${ }^{134}$. El caso de los Estados federales, donde el bicameralismo es una consecuencia prácticamente automática de la estructura federal, ilustra perfectamente sobre esa necesidad de que unos intereses, en este caso territoriales, participen en las decisiones políticas del Estado. Sin embargo, tal y como ocurrió en la Segunda República, «el radicalismo democrático, afirmando la validez exclusiva de la representación política individual y la escasa relevancia o riesgo de entorpecimiento de todos aquellos intereses, deriva lógicamente hacia el unicameralismo» ${ }^{135}$.

Desde esa perspectiva pueden imaginarse con mayor facilidad las diferencias entre una Segunda República sin Senado y otra con él. La introducción del bicameralismo hubiera supuesto la integración activa en el sistema de todos los intereses con los que se hubiera dotado a la composición de la segunda cámara, y sus consecuencias para el régimen hubieran derivado primor-

${ }^{134}$ ESTEBAN, 155 (Madrid, 1967): 43-75, ha señalado la gran ambigüedad que rodea a la idea de la representación de intereses, cuya significación depende, en última instancia, de la ideología o del grupo social que la adopte.

135 VARELA DÍAZ, 1978: 97. 
dialmente del hecho de esa integración. Puede llegarse así a tres conclusiones generales sobre las posibles repercusiones del bicameralismo en esta época. En primer lugar, se hubieran ensanchado las bases de aceptación del régimen, al comprometerse ciertos intereses en el funcionamiento del mismo ${ }^{136}$. El unicameralismo, por el contrario, provocó consecuencias diametralmente opuestas a las expresamente deseadas por sus partidarios. Pues, si lo que se pretendía era que la representación individual monopolizara la decisión parlamentaria, lo que se consiguió fue que los grupos de interés se infiltraran a través de los partidos políticos en la Cámara Baja, confundiéndose, en varias ocasiones, su acción y organización con las de aquéllos, lo cual complicaría enormemente el funcionamiento del sistema de partidos en las Cortes y la elaboración de las decisiones parlamentarias ${ }^{137}$.

En segundo término, aunque es difícil de precisar con exactitud, parece lógico que los intereses representados mediante el bicameralismo hubieran ejercido alguna influencia sobre la prioridad entre las medidas adoptadas durante esta época y la orientación de éstas. Algunos autores han coincidido en señalar cómo las Cortes prestaron una atención incomparablemente mayor a los problemas políticos o constitucionales que a los de índole social o económica y cómo, incluso al afrontar estos últimos, los enfoques ideológicos prevalecieron sobre perspectivas más pragmáticas o utilitarias ${ }^{138}$. Aunque, por supuesto, el fenómeno no deba achacarse exclusivamente al unicameralismo, tampoco puede despreciarse su influjo. Posiblemente, una segunda cámara podría haber presionado para evitar la lentitud exasperante de muchos proyectos legislativos, como la reforma agraria, constantemente postergada; quizá, la enorme carga ideológica con que se afrontó la cuestión religiosa se hubiera diluido en alguna medida; y, asimismo, podrían haberse evitado conflictos regionales, como el de los rabassaires en 1934, cuando el vacío político existente entre una Generalitat catalana de izquierdas y unas Cortes escoradas hacia la derecha únicamente podía salvarse mediante el puente jurisdiccional de un Tribunal de Garantías Constitucionales.

En tercer y último lugar, una Cámara de intereses, ya hubiera adoptado la forma de Senado corporativo o de Consejos Técnicos, habría podido desem-

136 RAMÍREZ JIMÉNEZ, 1969: 344, subraya, en este sentido, cómo «si un grupo no tiene conciencia de su participación en la elaboración de la política del país, si cree que sus intereses no han sido escuchados por los órganos decisorios, si piensa que su visión sobre el problema no tiene camino para ser expuesta, difícilmente dará luego por válidas esas reglas de un juego en el cual él no ha participado».

137 Como han puesto de manifiesto GUNTHER, SANI y SHABAD, 1986: 14-23, y JULIÁ, 20 (Madrid, 1995): 111-141.

${ }^{138}$ Así, ÁLVAREZ TARDÍO y VILLA GARCÍA, 2010: 97, consideran que tanto en la definición de la estructura de las Cortes como en la construcción del edificio constitucional «la ideología empañó el debate y proporcionó dosis demasiado elevadas de ambigüedad». 
peñar de alguna manera las funciones de un «parlamento industrial» ${ }^{139}$, es decir, un foro del capital y el trabajo capaz de actuar como pararrayos de la creciente lucha social. Se habría facilitado así una solución negociada entre fuerzas en conflicto, una alternativa viable al lock-out y la huelga revolucionaria. Con una segunda cámara de esta naturaleza, la posibilidad de avanzar en la democracia económica, complementando y equilibrando la democracia política puesta en pie por la Segunda República, se habría hecho realidad. La intervención de este órgano, aunque suponía la modificación sustancial en el sistema de representación del poder, era perfectamente asumible dentro de los objetivos generales del liberalismo. Si se frustró fue por la falta de perspectiva mostrada por fuerzas políticas incapaces de advertir la fragilidad a la que se sometía al sistema con el mantenimiento a ultranza del modelo unicameral. Es imposible dilucidar si este «parlamento industrial» hubiera logrado conjurar efectivamente el peligro de la lucha de clases y de la violencia asociada a ella, pero no parece descabellado sostener que los destinos del régimen republicano tampoco hubieran sido los mismos.

En definitiva, el bicameralismo hubiera introducido seguramente dos nuevas variantes en la actividad del Parlamento republicano: de una parte, una mayor preocupación hacia todas aquellas cuestiones que afectasen a los intereses representados en la segunda cámara; de otra, un mayor pragmatismo genérico en el tratamiento de los problemas. Esa doble influencia no llegaría, sin embargo, a percibirse nunca en su plenitud por los artífices de la Constitución de 1931.

\section{BIBLIOGRAFÍA}

Acosta Ramírez, Francisco, La Cámara elitista. El Senado español entre 1902 y 1923, Córdoba, Ayuntamiento de Córdoba, 1999.

Alcalá-Zamora, Niceto, «¿Cómo debería organizarse el futuro régimen?», $A B C, 2$ de febrero de 1928.

Alcalá-Zamora, Niceto, Los defectos de la Constitución de 1931, Madrid, Espinosa, 1936.

Álvarez Tardío, Manuel y Villa García, Roberto, El precio de la exclusión. La política durante la Segunda República, Madrid, Encuentro, 2010.

Álvarez Tardío, Manuel, «La CEDA y la democracia republicana», en Rey, Fernando del (dir.), Palabras como puños. La intransigencia política en la Segunda República española, Madrid, Tecnos, 2011; 341-418.

Arbeloa Muru, Víctor Manuel, ¿Una Constitución democrática? La Constitución española de 1931, Madrid, Mañana, 1977.

Azaña, Manuel, Obras Completas, México, Oasis, 1966-1968, 4 vols.

${ }^{139}$ Vid. sobre este concepto y su contextualización en la etapa inmediatamente posterior a la Primera Guerra Mundial la obra de BARRIO ALONSO, 1996: 63-71. 
Bar Cendón, Antonio, «El problema del voto de desconfianza en la Constitución Española de 1931», Revista de Derecho Político, 12 (Madrid, 1981-1982), 85-104.

Barrio Alonso, Ángeles, El sueño de la democracia industrial, Santander, Universidad de Cantabria, 1996.

Bertelsen Repetto, Raúl, El Senado en España, Madrid, Instituto de Estudios Administrativos, 1974.

Besteiro, Julián, «¿Cómo debería organizarse el futuro régimen?», $A B C, 1$ de marzo de 1928.

Bugallal, Gabino, «Examen de la reforma constitucional», $A B C, 18$ de julio de 1929.

Bühler, Ottmar, La Constitución alemana de 11 de agosto de 1919. Texto completo, comentarios, introducción histórica y juicio general, Barcelona, Labor, 1931.

Castillo Alonso, Gonzalo del, Derecho Politico y Constitucional comparado: comentarios a la Constitución española de 9 de diciembre de 1931, 3 ed., Barcelona, Bosch, 1932.

Castrillo Santos, Juan, Ante el drama de la reforma constitucional, Madrid, Bergua, 1935.

Cemboraín, Eugenio, La reforma constitucional en España, Madrid, Ambrosio Pérez y Compañía, 1907.

Contreras, Manuel, El PSOE en la II República: organización e ideología, Madrid, Centro de Investigaciones Sociológicas, 1981.

Cotta, Maurizio, «Il problema del bicameralismo-monocameralismo nel quadro di una analisi struttural-funzionale del Parlamento», Rivista Italiana di Scienza Politica, 1 (Milán, 1971), 545-595.

Duverger, Maurice, Instituciones politicas y derecho constitucional, $6^{\mathrm{a}}$ ed., Barcelona, Ariel, 1988.

Elorrieta, Tomás, «A lo que deberían limitarse las reformas constitucionales», El Sol, 23 de julio de 1929.

Esteban, Jorge de, «La representación de intereses y su institucionalización», Revista de Estudios Politicos, 155 (Madrid, 1967), 43-75.

Eza, Luis de Marichalar y Monreal, vizconde de, Ante el anuncio de reforma constitucional, Madrid, Ruiz Hermanos, 1928.

Fernández Sarasola, Ignacio, La responsabilidad del Gobierno en los orígenes del constitucionalismo español: 1808-1810, Oviedo, Universidad de Oviedo, 1996.

Fernández Sarasola, Ignacio, «El Senado en la historia constitucional española», en Balado, Manuel (dir.), La España de las Autonomías: reflexiones 25 años después, Barcelona, Bosch, 2005; 931-958.

Fernández Sarasola, Ignacio, «Cortes», en Fernández Sebastián, Javier y Fuentes, Juan Francisco (dirs.) Diccionario político y social del siglo XX español, Madrid, Alianza, 2008; 312-322.

Fernández Sarasola, Ignacio, Los partidos políticos en el pensamiento español. De la Ilustración a nuestros días, Madrid, Marcial Pons, 2009.

Fernández Segado, Francisco, Las Constituciones históricas españolas, Madrid, Instituto Católico de Artes e Industrias, 1981. 
Fraile Clivillés, Manuel María, Introducción al Derecho Constitucional español, Madrid, Sucesores de Rivadeneyra, 1975.

García Alix, Antonio, Funciones del rey en el régimen constitucional y parlamentario, Madrid, Real Academia de Ciencias Morales y Políticas, 1910.

García Canales, Mariano, El problema constitucional en la Dictadura de Primo de Rivera, Madrid, Centro de Estudios Constitucionales, 1980.

García Canales, Mariano, La teoría de la representación en la España del siglo XX, Murcia, Universidad de Murcia, 1977.

García Gallego, Jerónimo, Necesidad de Cortes Constituyentes. Replicando a La Época, al ABC y a significados hombres públicos de los partidos monárquicos, Valladolid, Imprenta Casa Social Católica, 1930.

García-Valdecasas, Alfonso, «La elaboración del texto constitucional», Revista de Estudios Políticos, 31-32 (Madrid, 1983), 57-70.

Gascón y Marín, José, «¿Cómo debería organizarse el futuro régimen?», $A B C, 12$ de febrero de 1928.

Gil-Robles, José María, No fue posible la paz, Barcelona, Planeta, 1968.

Giménez Martínez, Miguel Ángel, «El régimen parlamentario de la Segunda República y las relaciones entre su presidente, el Gobierno y las Cortes», Hispania Nova. Revista de Historia Contemporánea, 13 (Madrid, 2015), 54-77.

Giner de los Ríos, Francisco, La persona social, Madrid, Victoriano Suárez, 1899.

Gómez de Baquero, Eduardo, El colapso de la opinión liberal en España, Madrid, Gráf. Ambos Mundos, 1922.

Guillerm, André, La Constitution républicaine espagnole du 9 décembre 1931, Paris, Duchemin, 1933.

Gunther, Richard, Sani, Giacomo y Shabad, Goldie, El sistema de partidos políticos en España. Génesis y evolución, Madrid, Centro de Investigaciones Sociológicas, 1986.

Jiménez de Asúa, Luis, Proceso histórico de la Constitución de la República Española, Madrid, Reus, 1932.

Jiménez de Asúa, Luis, La Constitución de la democracia española y el problema regional, Buenos Aires, Losada, 1946.

Juliá, Santos, «Sistema de partidos y problemas de consolidación de la democracia», Ayer, 20 (Madrid, 1995), 111-141.

Juliá, Santos, La Constitución de 1931, vol. 8 de Artola, Miguel (dir.), Las Constituciones españolas, Madrid, Iustel, 2009.

Lamo de Espinosa, Emilio y Contreras, Manuel, Política y filosofía en Julián Besteiro, Madrid, Sistema, 1990.

Lario, Ángeles, «El modelo liberal español», Revista de Estudios Políticos, 122 (Madrid, 2003), 179-200.

Lario, Ángeles, «La difusión en España del "nuevo liberalismo": El Sol y la defensa de un Estado social de derecho», en Carantoña, Francisco y Aguado, Elena (eds.), Ideas reformistas y reformadores en la España del siglo XIX, Madrid, Biblioteca Nueva, 2008; 434-443 
Lesage, Michel, Les Régimes politiques de l'URSS et de l'Europe de l'Est, Paris, Presses Universitaires de France, 1971.

Lijphart, Arend, Democracies: Patterns of Majoritarian and Consensus Government in Twenty-One Countries, New Haven (CT), Yale University Press, 1984.

Lucas Verdú, Pablo, Curso de Derecho Político, Madrid, Tecnos, 1972-1984, 4 vols.

Madariaga, Salvador de, España. Ensayo de historia contemporánea, $6^{\mathrm{a}}$ ed., México, Hermes, 1955.

Massanet y Beltrán, Jerónimo, La reforma constitucional. Lo que se intenta y lo que debiera hacerse, Palma de Mallorca, Imprenta de Francisco Soler Prats, 1929.

McBain, Howard Lee y Rogers, Lindsay, The New Constitutions of Europe, Garden City (NY), Doubleday, Page \& co., 1922.

Minguijón, Salvador, «Hacia las reformas políticas», El Debate, 23 de febrero de 1928.

Montero Gibert, José Ramón, La CEDA: el catolicismo social y político en la II República, Madrid, Revista de Trabajo, 1977, 2 vols.

Mori, Arturo, Crónica de las Cortes Constituyentes de la Segunda República Española, Madrid, Aguilar, 1931-1934, 12 vols.

Muñoz Casillas, Juan, Los sistemas presidenciales, Madrid, Imprenta de Galo Sáez, 1929.

Ossorio y Gallardo, Ángel, Parlamento y Gobierno. Tres proyectos de ley, Madrid, Sociedad de Estudios Políticos, Sociales y Económicos, 1930.

Pemán, José María, El hecho y la idea de la Unión Patriótica, Madrid, Imprenta Artística Sáez Hermanos, 1929.

Pérez Ledesma, Manuel (coord.), El Senado en la historia, Madrid, Temas del Senado, 1995.

Pérez Serrano, Nicolás, La Constitución Española (9 diciembre 1931). Antecedentes, texto, comentarios, Madrid, Editorial Revista de Derecho Privado, 1932.

Posada, Adolfo, La crisis del Estado en el Derecho Político, Madrid, Bermejo, 1934.

Posada, Adolfo, La nouvelle Constitution espagnole. Le régime constitutionnel en Espagne: Évolution, textes, commentaires, Paris, Sirey, 1932.

Posada, Adolfo, La reforma constitucional, Madrid, Librería General de Victoriano Suárez, 1931.

Prieto, Indalecio, Discursos fundamentales, Madrid, Turner, 1975 (con prólogo de Edward Malefakis).

Ramírez Jiménez, Manuel, Los grupos de presión en la Segunda República española, Madrid, Tecnos, 1969.

Ramírez Jiménez, Manuel, Las reformas de la II República, Madrid, Túcar, 1977.

Roig Ibáñez, Vicente, La Constitución que necesita España, Madrid, Javier Morata, 1930.

Royo-Villanova, Antonio, «Cómo debería organizarse el futuro régimen?», $A B C, 17$ de febrero de 1928.

Royo-Villanova, Antonio, La Constitución española de 9 de diciembre de 1931 con glosas jurídicas y apostillas políticas, Valladolid, Imprenta Castellana, 1934.

Ruiz Lapeña, Rosa María, El Tribunal de Garantías Constitucionales de la II República Española, Barcelona, Bosch, 1982. 
Ruiz Lapeña, Rosa María, «La alternativa bicameral en el proceso constituyente de 1931», Ius Fugit. Revista interdisciplinar de estudios histórico-jurídicos, 7 (Zaragoza, 1998), 344-346.

Saracíbar, Julio de, La reforma de la actual composición del Senado, Madrid, Imprenta y Encuadernación de Julio Cosano, 1921.

Schmitt, Carl, Teoría de la Constitución, Madrid, Editorial Revista de Derecho Privado, 1934.

Sierra, María, Peña Guerrero, María Antonia y Zurita, Rafael, Elegidos y elegibles. La representación parlamentaria en la cultura del liberalismo, Madrid, Marcial Pons, 2010.

Tomás Villarroya, Joaquín, El sistema político del Estatuto Real, Madrid, Instituto de Estudios Políticos, 1968.

Tomás Villarroya, Joaquín, «El presidente Alcalá-Zamora y el proyecto de reforma constitucional de 1935», Cuadernos de la Cátedra Fadrique Furió Ceriol, 2 (Valencia, 1976), 20-35.

Tomás Villarroya, Joaquín, Breve historia del constitucionalismo español, Madrid, Centro de Estudios Constitucionales, 1981.

Tomás Villarroya, Joaquín, «Presidente de la República y Gobierno: sus relaciones», Revista de Estudios Politicos, 31-32 (Madrid, 1983), 71-100.

Torres del Moral, Antonio, Constitucionalismo histórico español, Madrid, Átomo Ediciones, 1988.

Tsebelis, George y Money, Jeannette, Bicameralism. Political Economy of Institutions and Decisions, Cambridge, Cambridge University Press, 1997.

Tusell, Javier, Historia de la democracia cristiana en España, Madrid, Sarpe, 1986, 2 vols.

Varela Díaz, Santiago, Partidos y Parlamento en la Segunda República, Madrid, Fundación Juan March-Ariel, 1978.

Varela Suanzes-Carpegna, Joaquín, «El debate sobre el sistema británico de gobierno en España durante el primer tercio del siglo XIX», en Alvarado, Javier (coord.), Poder, Economía y Clientelismo, Madrid, Marcial Pons, 1997; 97-124.

Vázquez del Campo, Antonio, Hacia la reforma constitucional de España, Madrid, Reus, 1929.

Vidarte, Juan Simeón, Las Cortes Constituyentes de 1931-33. Testimonio del Primer Secretario del Congreso de los Diputados, Barcelona, Grijalbo, 1976.

Zancada, Práxedes, Los problemas constitucionales de España, Madrid, Compañía Iberoamericana de Publicaciones, 1930.

Zapatero, Virgilio, Fernando de los Ríos: los problemas del socialismo democrático, Madrid, Edicusa, 1974.

Recibido: 20/10/2014

Aprobado: 26/05/2015 